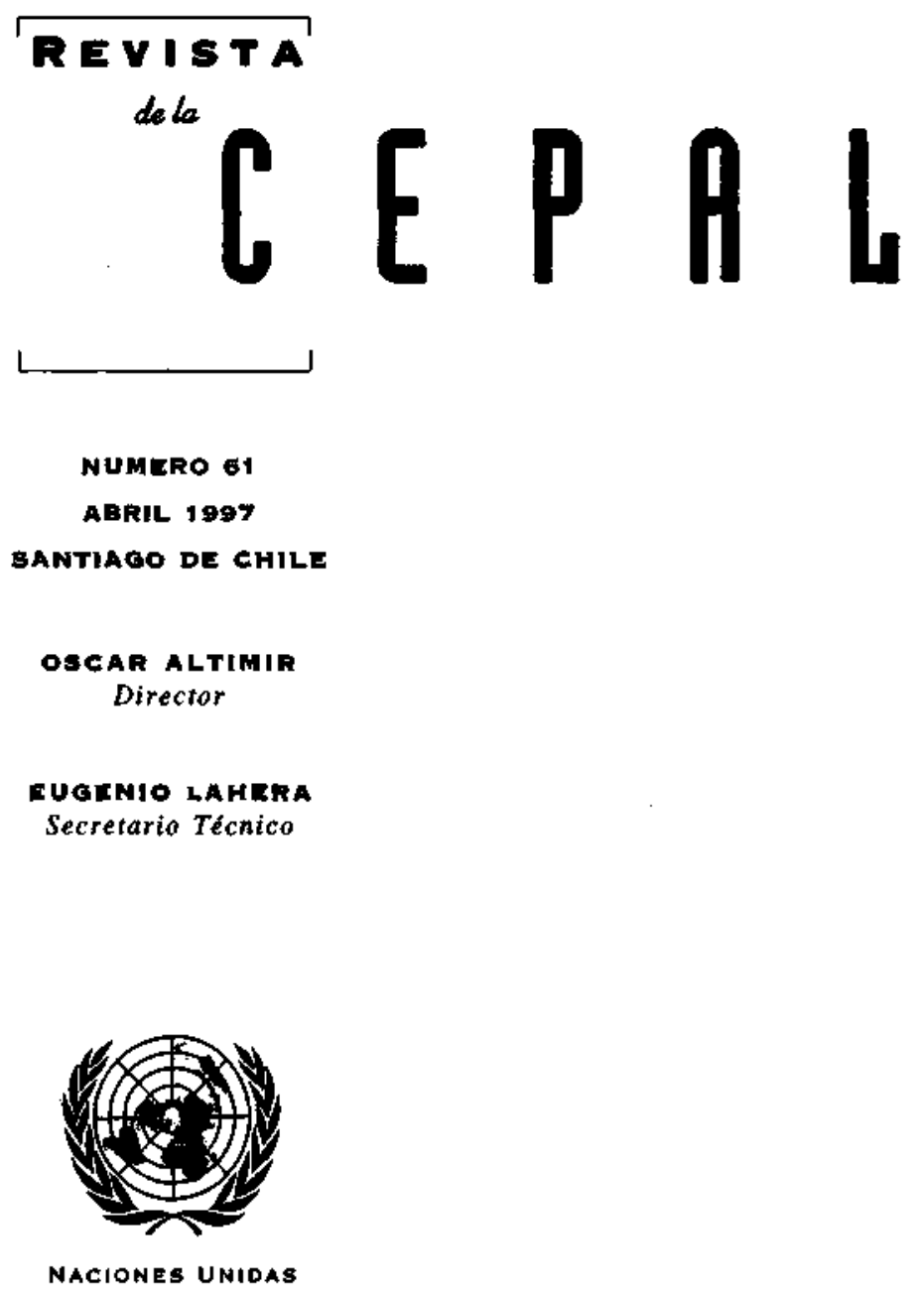


Tres formas de coordinación social

Norbert Lechner

Brechas sociales en Colombia

Juan Luis Londoño de la Cuesta

Los Estados Unidos al rescate: la asistencia financiera a México

en 1982 y 1995

Nora Lustig

El régimen de convertibilidad y el sistema bancario en la Argentina

Alfredo F. Calcagno

Exportaciones de manufacturas: desatios para las pequeñas economías de América Latina

Rudolf M. Buitelaar, Pitou van Dijck

¿Por qué las inversiones en el transporte público no reducen la congestión de tránsito urbano?

Ian Thomson

Notas sobre la medición de la pobreza según el método del ingreso

Juan Carlos Feres

La politica fiscal y el ciclo económico en Chile

Carlos Budnevich, Guillermo Le Fort

Evaluación de la política de bienes de capital en la Argentina

Pablo Sirlin

Reestructuración de los grupos industriales brasileños entre 1980 y 1993

Ricardo M. Ruiz

Reestructuración productiva y cambio territorial: un segundo eje de industrialización en el norte de México

Tito Alegría, Jorge Carrillo, Jorge Alonso Estrada

Publicaciones recientes de la CEPAL 


\section{Brechas sociales en Colombia}

\section{PHD Universidad de Harvard. Ex Ministro de Salud de Colombia. Oficina del Economista Jefe, Banco Interamericano de Desarrollo (BN)}

Juan Luis Londoño de la Cuesta
Este artículo analiza los niveles y la evolución de las desigualdades sociales en Colombia en los últimos 25 años, describiendo las principales tendencias recientes del desarrollo social colombiano, comparándolas con períodos historicos previos y contrastándolas con las de otros países. Ante todo se presenta una estimación reciente de la distribución del ingreso y el resto de los indicadores sociales. En seguida, se analizan las tendencias distributivas del ingreso monetario en el período 1938-1993, se examina el impacto del gasto social sobre la distribución secundaria del ingreso y sobre estas bases se evalúan las tendencias en la distribución del ingreso efectivamente recibido por los individuos. Luego se describe y compara la evolución de la pobreza y de otros indicadores de bienestar. Por último se formulan algunas reflexiones sobre las perspectivas sociales en Colombia. Se concluye que el país ha experimentado enormes cambios distributivos y de bienestar que han ido reduciendo la desigualdad y la pobreza, pero que al parecer ha habido un desplazamiento de los problemas sociales predominantes en el país, ya que las insuficiencias y desigualdades en el nivel educativo y las esperanzas de vida de la población joven habrían comenzado a tener un papel dominante. 
I

\section{Introducción}

Colombia es un país de paradojas. Su dinámica de crecimiento económico en los últimos 50 años es la más estable de todo el continente latinoamericano. Su democracia es la de mayor persistencia en toda la región. Su estructura productiva ha registrado una transformación dos veces más rápida que en la mayoría de los países latinoamericanos. Su economía ha evitado las irrupciones inflacionarias que han caracterizado en algún momento a casi todos estos países. Sin embargo, los colombianos y los estudiosos de Colombia en el exterior perciben claramente que éste es un país con enormes tensiones sociales, cuya manifestación más abierta es la violencia. En cada uno de los últimos años ha habido en Colombia alrededor de 25000 homicidios, lo que supera los 15000 de toda Europa o los 23000 de los Estados Unidos (Naciones Unidas, 1995). La guerrilla colombiana es la más antigua del continente, y la ansiedad de la gente respecto de la sociedad es enorme.

La irrupción de la violencia se interpreta frecuentemente en los análisis del país como una expresión del deterioro de sus condiciones sociales. En los años sesenta Colombia tenía una de las peores distribuciones del ingreso del mundo (Urrutia y Berry, 1975); hoy muchos analistas internacionales persisten en ver el país como una sociedad estructuralmente desigual. ${ }^{1}$ Desde finales de los años ochenta el país emprendió ajustes a su modelo económico para impulsar la apertura y la competitividad de la economía (Colombia, Departamento Nacional de Planeación, 1991); algunos analistas colombianos, ${ }^{2}$ con bastante eco en los círculos académicos internacionales, ${ }^{3}$ han considerado que

$\square$ Agradezco la colaboración de Hemando Moreno Guerrero, de Olga Lucía Jaramillo, Alejandro Mateus, María Cristina Pefialoza y Martha \$ánchez del Departamento Nacional de Plameación (DNP), y de Jairo Urdaneta del Departamento Administrativo Nacional de Estadistica (DANE) en el procesamiento y la adecuada interpretación de la información utilizada.

${ }^{1}$ Como Berry (1995a); Cardoso y Helwege (1992) y Palacios (1995). Este último, por ejemplo, afirma: "Colombia ofrece uno de los peores cuadros en cuanto a distribución del ingreso de América Latina y por tanto del mundo" (p. 289).

${ }^{2}$ Especialmente E. Sarmiento (1993 y 1995) y L. Sarmiento (1993 y 1995).

${ }^{3}$ Por ejemplo, Berry (1995b). tales políticas económicas - tildadas en forma simplista de neoliberales- habrían contribuido a un grave deterioro social.

Infortunadamente, la mayor parte del debate reciente sobre el efecto de las políticas económicas en la distribución del ingreso o la situación social ha tenido un referente empírico bastante débil. Los argumentos no siempre se sostienen en pruebas contundentes, que permitan cotejar esas variables a lo largo del tiempo y compararlas con las de otras naciones. El rezago en el procesamiento de la información impide una adecuada identificación de tendencias, y cada nuevo gobierno, con el fin de enaltecer ante la opinión pública la novedad de sus políticas, hace lecturas no siempre completas del progreso social de los períodos anteriores.

Este breve ensayo, que describe los niveles y la evolución de las desigualdades sociales colombianas en los últimos 25 años, arroja dos conclusiones.

Del artículo se desprende que la desigualdad distributiva y la pobreza absoluta están comenzando a dejar de ser los problemas sociales dominantes en Colombia. El progreso de los últimos 25 años en esta materia ha sido poco menos que espectacular. El vertiginoso avance económico generó enormes cambios distributivos y de bienestar, reduciendo la desigualdad y la pobreza, y el mayor gasto social en la población más pobre generado por la Constitución de 1991 fortalecío el progreso distributivo, que se aceleró en los años noventa.

Sin embargo, la evolución reciente de los indjcadores de bienestar probablemente refleje una nueva jerarquización de los problemas sociales predominantes en el país. Las desigualdades en el nivel educativo y las esperanzas de vida de la población joven habrían pasado a desempeñar un papel dominante. La dinámica distributiva del petíodo reciente indica que la escasez de capital humano en Colombia, frente a las demandas de una economía en rápido crecimiento y de un contexto internacional con niveles educativos cada vez más altos, comienza a manifestarse con fuerza inusitada. Y la espiral de violencia de la última década ha generado una juventud con las menores esperanzas de vida de toda América Latina, lo que causa zozobra e incertidumbre y mina el capital social. 


\section{La situación social actual}

A mediados de los años noventa Colombia es un país con mucha desigualdad y pobreza. La disparidad del ingreso es marcada. La forma más simple de mostrarlo es a través de la curva de Lorenz de la distribución del ingreso en 1993 (gráfico 1). En ese año el quintil más pobre de la población recibía el $4 \%$ del ingreso nacional, la mitad más pobre recibía el $18.7 \%$ y el quintil más rico el $52.5 \%$. Así, el $20 \%$ más rico percibía 13 veces más ingresos que el $20 \%$ más pobre. Los ingresos medios más bajos eran aquéllos de los campesinos y los jornaleros agrícolas, y el quintil más pobre estaba compuesto en un $60 \%$ por familias campesinas y de trabajadores independientes (cuadro 1). ${ }^{4}$

Actualmente, nueve millones y medio de colombianos viven en la pobreza, cualquiera que sea la definición que se le dé a ésta. En efecto, aproximadamente el $27 \%$ de la población tiene ingresos diarios que quedan por debajo de las líneas de pobreza internacionalmente aceptadas o al menos una de sus necesidades básicas está insatisfecha ${ }^{5}$ (cuadro 2). La esperanza de vida es de 69.1 años, pero esta cifra esconde grandes diferencias entre los grupos sociales. El 25\%

\section{GRAFCQO I}

Colombla: La curva de Lorenz, 1993

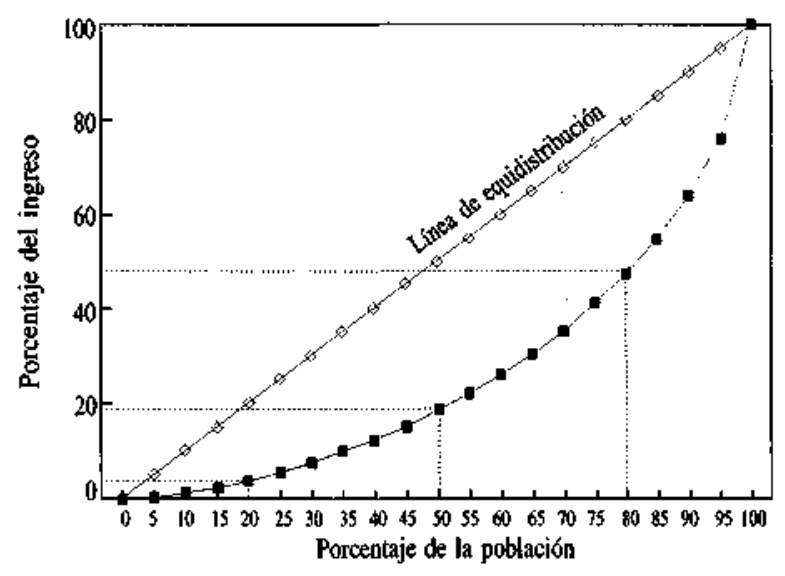

\footnotetext{
4 Para más detalles, véase el anexo 1. Véanse también datos conparables en Londoño (1995b), anexo estadístico.

${ }^{5}$ De acuerdo con CEPAL (199I), estas necesidades básicas familiares son vivienda digna (no hacinada), servicios básicos de agua potable, educación básica para los hijos y empleo para al menos uno de los miembros adultos del hogar.
}

\begin{tabular}{lcc}
$\begin{array}{l}\text { CUADRO I } \\
\text { Colombia: La distribución del ingreso } \\
\text { en } 1993\end{array}$ \\
\hline $\begin{array}{l}\text { Indicadores agregados } \\
\text { Coeficiente Gini }\end{array}$ & 0.47207 \\
Coeficiente de Theil & 0.39303 & \\
Indice de Atkinson & 0.55977 & \\
Varianza logaritmica & 0.9950 & \\
& & \\
Indicadores desagregados & Coeficiente & Ingreso medio \\
& Gini & (dólares por afio) \\
Jornaleros & 0.3037 & 1616 \\
Campesinos & 0.5283 & 1370 \\
Rentistas & 0.5334 & 4721 \\
Asalariados & 0.3827 & 2963 \\
Trabajadores por & & 2636 \\
cuenta propia & 0.5465 & 7561 \\
Capitalistas & 0.4737 & 12781 \\
& &
\end{tabular}

CUADRO 2

Colombia: Indicadores sociales, 1993-1995

\begin{tabular}{ll}
\hline De desigualdad & \\
Coeficiente Gini & 0.472 \\
Participación del 20\% más pobre & 4.0 \\
Participación del $40 \%$ mas pobre & 12.6 \\
Participación del $20 \%$ más rico & 52.5 \\
& \\
De pobreza & \\
Por ingreso insuficiente (1993) & $27.2 \%$ \\
Por necesidades basicas insatisfechas (1994) & $27.1 \%$ \\
& \\
De desarrollo humano & 0.836 \\
Indice de desarrollo humano & 5.9 \\
Años de educación (1994) & 69.1 \\
Esperanza de vida (1995) & 20 \\
Mortalidad de niños (1993) & $25 \%$ \\
Falta de cobertura de salud & $5 \%$ \\
Falta de cobertura de la educación básica & 5.6 \\
\hline
\end{tabular}

astos indicadores son los más actualizados disponibles.

de la población más pobre cuando se enferma no tiene acceso a los servicios de salud. El $21 \%$ de los niños nace sin asistencia alguna del personal de salud, el 13\% sufre de desnutrición y el $2 \%$ muere antes de cumplir los cinco años. La escolaridad media de la fuerza de trabajo es de 5.9 años, y también esconde grandes variaciones sociales. Aunque el $95 \%$ de los niños comienza la educación básica, el $83 \%$ de niños entre los 
6 y los 11 años asiste a la escuela, y el $44 \%$ más pobre de ellos no termina el quinto año de primaria.

Estos indicadores son bien conocidos y generalmente aceptados entre Ios analistas colombianos, y suelen proporcionar, con razon, argumentos a los críticos de la sociedad colombiana y de sus políticas económicas y sociales. Lo sorprendente es que estos mismos indicadores también han servido a los cuatro últimos gobiernos para sostener la orientación social de sus respectivos planes de desarrollo: Desarrollo con Equidad (Betancur, 1982-1986), Plan contra la Pobre- za Absoluta (Barco, 1986-1990), La Revolución Pacífica (Gaviria, 1990-1994) y El Salto Social (Samper, 1994-1996).

Sin embargo, el significado de los indicadores actuales se aprecia mucho mejor cuando se les analiza en forma dinámica - respecto de su evolución previa en el país- y comparativa, respecto de otros países en similares condiciones de desarrollo. Es lo que veremos en las siguientes secciones, donde se examinan los cambios en la distribución del ingreso, la pobreza y los principales indicadores de desarrollo humano.

\section{III}

\section{Las tendencias distributivas del ingreso primario en 1938-1993}

La distribución del ingreso entre las familias puede conceptualizarse como si se llevase a cabo en dos rondas (Okun, 1975). En la primera, el ingreso fluye desde la producción hacia los factores que en ella participan, en calidad de retribución del trabajo, retornos del capital y rentas: esta es la distribución primaria del ingreso, que se examina en esta sección. En la segunda ronda, el sector externo y el Estado median para redistribuir el ingreso generado entre los diversos agentes: esta es la redistribución secundaria del ingreso a través del gasto social, que se analiza en la sección IV.

En la mayoría de los países la comparación de los indicadores de ingreso a lo largo del tiempo suele presentar enormes dificultades metodologicas. Las encuestas de hogares casi siempre exhiben diferencias en la cobertura y las definiciones, y las apreciaciones a partir de ellas están casi siempre sujetas a grandes polémicas. ${ }^{6}$ Este trabajo continúa una línea de investigación que pone el máximo cuidado en la construcción

\footnotetext{
${ }^{6}$ En Colombia los mayores debates sobre los cambios distributivos se concentraron en los años setenta y los noventa. A mediados de la década de 1970 muchos autores creyeron encontrar un grave deterioro de la distribución del ingreso (una buena síntesis de los argumentos se encuentra en Samper, 1976, e Eastman, 1979), mientras otros encontraban evidencia de lo contrario (véanse especialmente Unutia, 1985; Londoño, 1989; Carrisoza y Urdinola, 1990). Los años noventa también han sido un período de enorme debate: E. Sarmiento (1993 y 1995) y L. Sarmiento (1993 y 1995) señalaron un grave deterioro, en tanto que Urrutia y Ramírez (1993) así como Urrutia, Misas, Ramírez y Rodríguez (1994), presentaron evidencia contraria.
}

de indicadores sobre la distribución del ingreso y la pobreza que sean comparables en el tiempo y entre países. La esencia de la metodología es lograr que la información sobre empleo y dispersión poblacional de los distintos tipos de ingreso (como salarios, rentas y ganancias) provistos por las encuestas de hogares sean compatibles con la distribución factorial del ingreso de los hogares provisto por las cuentas nacionales, ${ }^{7}$ después de descontar el consumo de capital.

\section{La distrlbución factorial del ingreso nacional}

El hecho distributivo más notable registrado en Colombia durante el siglo XX ha sido la cambiante participación del trabajo en el ingreso nacional (neto de depreciación). En medio de algunas fluctuaciones cíclicas, la participación del trabajo ha descrito en el largo plazo una clara curva en forma de $\mathrm{U}$ (gráfico 2): tras representar más del $60 \%$ del ingreso nacional a fines de los años treinta, descendió hasta el $50 \%$ al final de los cincuenta y ascendió en los 35 años siguientes hasta alcanzar el $70 \%$ del ingreso nacional a mediados de los años noventa.

La distribución del ingreso puede desagregarse aún más entre sus diversos factores. Los ingresos del trabajo están compuestos por remuneraciones al trabajo

\footnotetext{
${ }^{7}$ La metodología fue diseñada por el autor para su tesis doctoral en la Universidad de Harvard. Está plenamente explicada en el anexo estadístico de Londofio (1995b) y en el capítulo 1 de DANE (1994b).
} 
GRAFICO 2

Colombla: La participación del trabajo en el ingreso nacional, 1938-1993

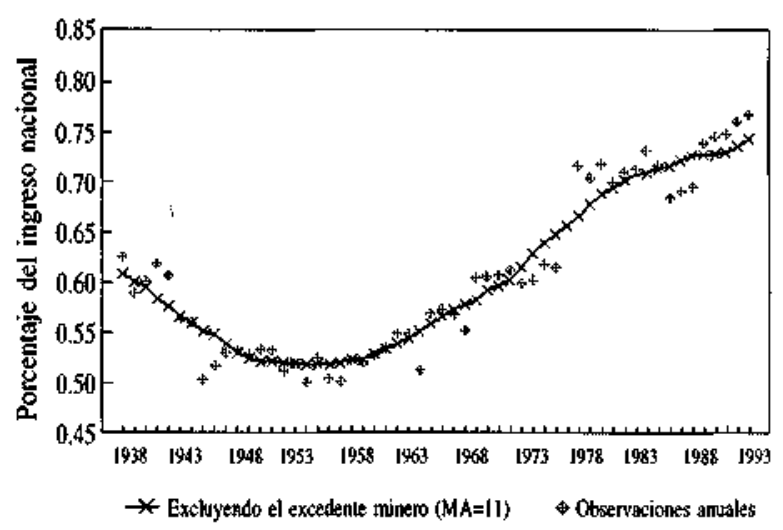

puro y por remuneraciones al capital humano. Los ingresos no laborales, a su vez, se componen de las ganancias del capital invertido en las actividades urbanas y las rentas de la tierra en agricultura y minería ${ }^{8}$ (véase en el gráfico 3 cómo evolucionó la participación de cada uno de estos factores en el ingreso nacional entre 1938 y 1993).

Es evidente que la cambiante participación del trabajo en el ingreso nacional es el resultado de tres tendencias que se superponen. De una parte, la contribución del trabajo puro agrícola se redujo continuamente: tras representar el $30 \%$ del ingreso en los años treinta, su descenso se aceleró en los sesenta y llegó al $10 \%$ en los noventa. ${ }^{9}$ De otra parte, la retribución al trabajo no agrícola aumentó su participación en el ingreso nacional del $30 \%$ en los años treinta al $55 \%$ en los noventa, como producto del proceso de migración y de una dinámica productiva crecientemente urbana. En la remuneración del trabajo urbano, a su vez, adquirió cada vez más importancia la retribución al capital humano, que creció a un ritmo particularmente rápido con el auge educativo de los años sesenta.

\footnotetext{
${ }^{8}$ El trabajo puro valora a todas las personas que declaran tener empleo a los salarios básicos declarados por los trabajadores sin educación. El capital humano resulta de la diferencia entre los ingresos medios del trabajo (asalariado e independiente) y la remuneración al trabajo puro. Las ganancias urbanas resultan de descontar del valor agregado no primario los ingresos del trabajo y la depreciación del capital. Las rentas de la tierra se obtienen al descontar del valor agregado agrícola y minero los salarios y las remuneraciones del capital.

${ }^{9}$ Las actuales cuentas nacionales, que se concentran en el trabajo asalariado de la agricultura e incorporan muy poca información sobre la dinámica del empleo observado en las encuestas de hogares, no pueden reflejar la evolución aquí descrita.
}

Los ingresos no laborales, por su parte, tienen tres componentes. Las ganancias de las empresas urbanas, descontada la depreciación, han disminuido continuamente su participación en el ingreso nacional durante todo el siglo, debido a que la rentabilidad del capital descendió más rápidamente que la relación PIB-capital. Las rentas de la tierra dedicada a la agricultura aumentaron su participación en el PIB desde los años treinta hasta fínales de los cincuenta -en gran parte gracias al auge cafetero $\rightarrow$ y bajaron a partir de entonces a un ritmo que se hizo especialmente rápido al final de los años setenta. Por último, las rentas derivadas de la explotación minera, que descendieron continuamente desde los años cincuenta hasta el final de los setenta (hasta llegar a $1.2 \%$ del ingreso), se elevaron enormemente desde mediados de los años ochenta, gracias a la actividad carbonífera y petrolera, hasta alcanzar el $8.0 \%$ del ingreso nacional en la primera mitad de los años noventa.

Queda claro así que Colombia exhibe un ciclo de largo plazo en la distribución factorial del ingreso, en el cual el capital humano y el trabajo puro urbano han ganado participación en el ingreso nacional, al tiempo que la han perdido las ganancias urbanas y el trabajo puro agrícola. Como lo muestra Londoño (1995b), lo sucedido es explicable por los desplazamientos de la acumulación de capital mentre actividades urbanas y rurales, entre capital físico y capital humano-y los cambios de localización espacial de la fuerza de trabajo. Además del ciclo de largo plazo, en el país se registran ciclos de mediano plazo que han sido determinados por el ascenso de las rentas de la tierra agrícola en las primeras décadas de la posguerra y el incremento de los excedentes mineros desde mediados de los años ochenta, ambos impulsados en gran medida por los cambios en el uso del suelo inducidos por los precios internacionales.

\section{La distribución del ingreso de las familias}

Para entender la distribución del ingreso de las familias es preciso efectuar otros dos procedimientos empíricos. Primero, hay que reconstruir el ingreso global de las familias; para ello se deduce del ingreso nacional neto el excedente que nunca llega a los hogares porque se queda en las empresas. ${ }^{10}$ Segundo, hay que atribuir este ingreso global de las familias a seis distintos grupos de receptores de ingreso: los trabajado-

\footnotetext{
${ }^{10}$ En $1970-1993$, un promedio de $43.5 \%$ del excedente generado fue retenido por las empresas.
} 

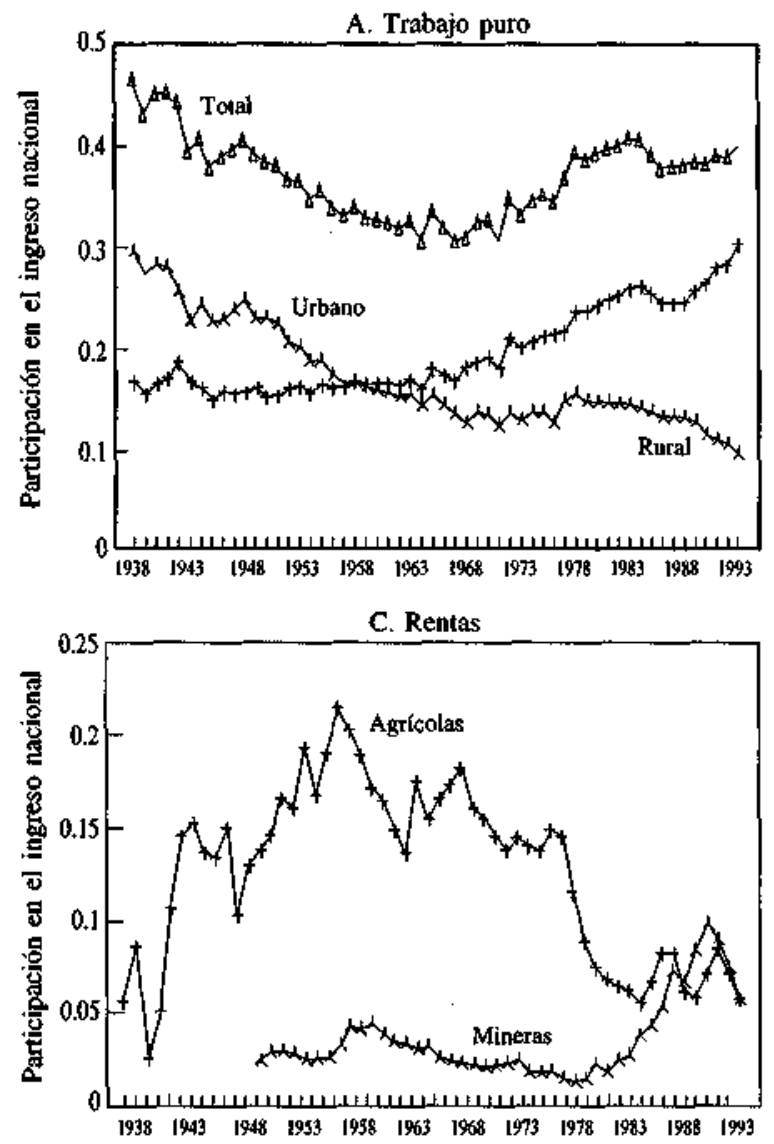

Fuente: DANE, con la metodología de Londoño (1995b).

res agrícolas asalariados, los campesinos, los asalariados urbanos, los trabajadores por cuenta propia urbanos, los perceptores de rentas agrícolas y los capitalistas urbanos. La cuenta de los hogares de las cuentas nacionales sirve de marco de consistencia para analizar la distribución factorial del ingreso familiar en aquellos años para los cuales las encuestas de hogares permiten identificar los perceptores de ingreso. ${ }^{11}$

Así pues, los hogares han reflejado los cambios de largo plazo en la distribución del ingreso nacional mencionados antes: aumentó la proporción del ingre-

\footnotetext{
II El cuadro 31 de las cuentas nacionales del DANE (1994a) necesita algunos ajustes para este propósito. Primero, de las cuentas del excedente se deducen los fondos de depreciacion atribuibles a los hogares, así como los ingresos de los trabajadores independientes en todos los sectores. Fínalmente, el valor agregado agrícola se redistribuye entre remuneraciones al capital, rentas, remuneraciones al trabajo independiente y salarios, de acuerdo con la información del mercado de trabajo.
}
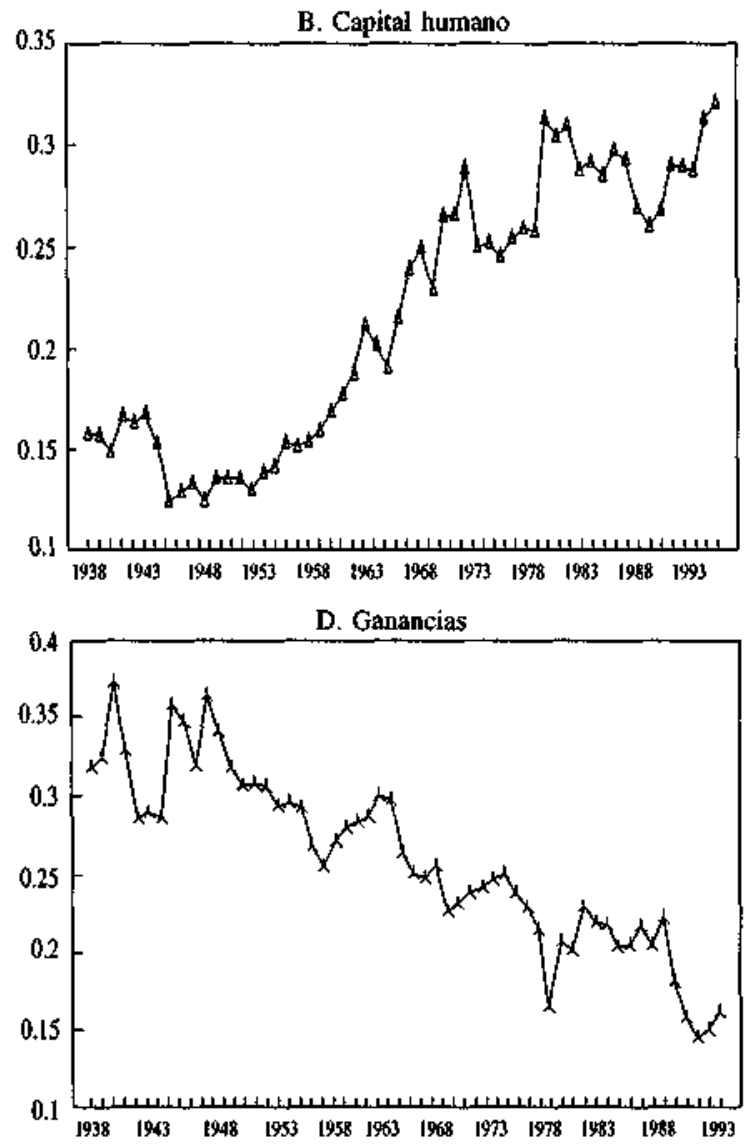

so de las familias que proviene de ingresos laborales (que alcanzó su mínimo de $56 \%$ en el año 51 y su máximo de $85 \%$ durante la presente década) y disminuy6, especialmente desde los años cincuenta, la fracción del ingreso proveniente de ganancias urbanas y rentas de la tierra (gráfico 4). Pero no todos los cambios en la distribución del ingreso nacional se reflejan en las cuentas de los hogares. Los hogares no fueron partícipes del auge de las rentas de la explotación minera en los ochenta, por lo cual su mayor dinamismo continuó proveniendo de los ingresos laborales. En la agricultura, fueron los campesinos los que registraron la mayor pérdida de ingreso, por haber experimentado oscilaciones más marcadas en sus salarios y empleo. Los trabajadores independientes de las ciudades, por su parte, han continuado aumentando su participación en el ingreso desde los años sesenta, aunque a partir de mediados de los años ochenta el empleo informal ha perdido sistemáticamente participación en el 
GRAFICO 4

Colombia: Distribución del ingreso de los hogares, 1938-1993
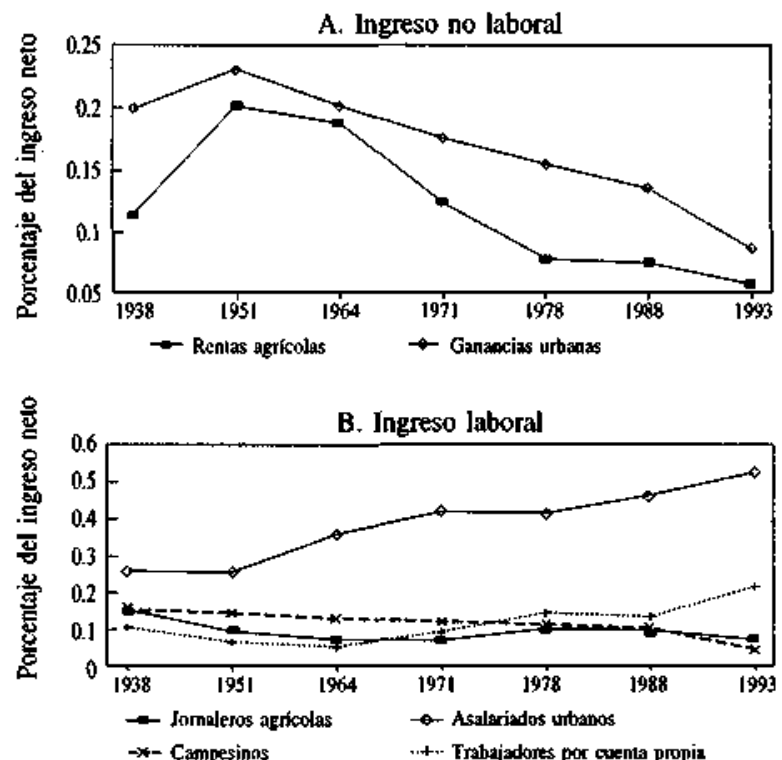

mercado de trabajo (Caro y Rodríguez, 1993; López, 1995).

\section{La distribución del Ingreso entre individuos}

La información sobre el ingreso de las familias obtenida de las cuentas nacionales y conciliada con la información de las encuestas de hogares sobre el empleo y la dispersión del ingreso de los distintos receptores, permite obtener estimaciones de la distribución del ingreso entre individuos comparables a lo largo del tiempo. ${ }^{12}$

\footnotetext{
12 Para el periodo 1938-1988, las fuentes y metodologia se hallan en Londofio, I995b. El análisis para 1993 se basa en la Encuesta CASEM realizada por el Departamento Nacional de Planeación sobre una muestra de 25000 hogares con 130000 informantes (junio de 1993). Otros autores han seleccionado las encuestas de hogares realizadas por el DANE durante tal periodo (especialmente la EH77 de 1992) que, como lo sefialo E. Sarmiento, 1993, tienen truncada la codificación de los ingresos más altos, por lo cual tienden a subestimar la desigualdad. Urrutia, Misas, Ramírez y Rodríguez (1994) y E. Sarmiento (1995) trataron de corregir este sesgo de la información primaria con métodos estadísticos, suponiendo formas funcionales y parámetros de la distribución. Ambos procedimientos, que por concentrarse en la distribución del ingreso por hogares ignoran la información de los individuos que está truncada o no declarada, siguen siendo respuestas muy imperfectas a la debilidad de la Información primaria. Por esta razón, he preferido utilizar una encuesta como la casem, que está libre de tal problema y por lo tanto supera esta célebre y aguda polémica.
}

GRAFCO 5

\section{Colombla: Evolución de la distribución del} ingreso, 1938-1993

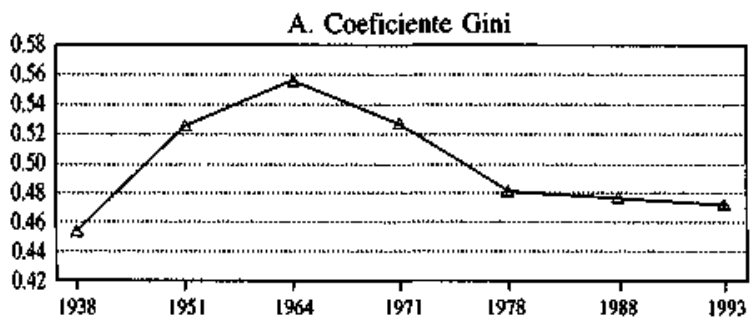

B. Coeficiente de entropia de Theit

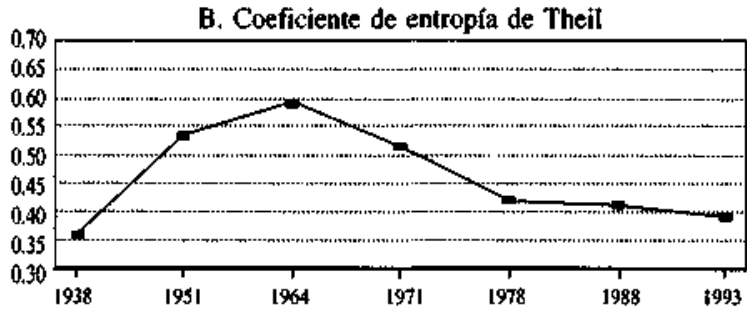

Los dos indicadores más utilizados para representar la desigualdad de la distribución del ingreso son el coeficiente de entropía de Theil y el coeficiente Gini (gráfico 5). Ambos indicadores resultan consistentes para identificar las diferentes fases de la evolución distributiva colombiana durante este siglo.

Entre los años treinta y los sesenta la distribución del ingreso en Colombia presentó un gran deterioro. El coeficiente Gini aumentó más de 10 puntos y el coeficiente de Theil casi 25 puntos. Según Londoño (1995b), ${ }^{13}$ la combinación de modalidades de acumulación de capital y movilidad del trabajo explican este resultado. La veloz acumulación de capital urbano, junto con la lenta expansión de la educación hasta finales de los años cincuenta, habría generado una creciente desigualdad en la estructura de las remuneraciones urbanas, con una muy alta rentabilidad de la educación. A su vez, la lenta modernización de la agricultura unida a la débil expulsión de trabajadores hacia las ciudades, a su vez, habría estancado los salarios rurales, elevado las rentas de la tierra y acentuado la desigualdad de los ingresos derivados de la agricultura.

Entre finales de los años sesenta y comienzos de los ochenta hubo un rápido progreso distributivo. El coeficiente Gini baj6 8 puntos y el coeficiente de Theil 18 puntos, revirtiendo casi el deterioro distributivo de

\footnotetext{
${ }^{13}$ Con ejercicios chiométricos que hacen uso de modelos computables de equilibrio general para el análisis histórico, Londôno (1995b) realiza los ejercicios contrafacticos que permiten poner a prueba la validez de estas hipótesis explicativas.
} 
la fase anterior. Las variaciones en las modalidades de acumulación y en la movilidad del trabajo también fueron aquí los principales causantes del cambio distributivo. El rápido aumento de la acumulación de capital humano al tiempo que la relación capital-prB en las zonas urbanas permanecía estable, comprimió la estructura salarial y la rentabilidad de la educación. Por otra parte, la ocurrencia simultánea de la capitalización agrícola —especialmente en mejoramiento de tierrascon el incremento de la migración hacia las ciudades habría permitido eliminar el exceso de mano de obra rural. Con ello, aumentaron considerablemente las remuneraciones de los trabajadores agrícolas, disminuyeron las rentas de la tierra y mejoró sustancialmente la distribución de las rentas rurales.

Desde los años ochenta hasta mediados de los noventa hubo una fase de progreso distributivo positivo pero lento, especialmente comparado con la fase previa. El coeficiente Gini se redujo algo menos de un punto y el coeficiente de entropía de Theil algo menos de tres puntos en esos 15 años. Esta desaceleración del progreso distributivo tuvo dos componentes, uno de largo plazo y otro de corto plazo.

En las tendencias de largo plazo, el aumento de la participación de los salarios y de los ingresos independientes urbanos en el ingreso nacional se mantuvo a costa de una menor participación relativa de los trabajadores agrícolas, las ganancias urbanas y las rentas de la agricultura. Sin embargo, la dinámica de acumulación de los años sesenta, que condujo a los cambios distributivos posteriores, se debilitó considerablemente en la década de 1980. La expansión educativa se hizo mucho más lenta, y el número de años de escolaridad de la fuerza de trabajo comenzó a reflejarlo. Asimismo, la capitalización de la agricultura perdió el gran dinamismo que había exhibido en los decenios de 1960 y 1970 . Estos dos factores aminoraron las presiones tanto para disminuir la desigualdad laboral por la vía de la estructura salarial y la rentabilidad de la educación, como para reducir la demanda de mano de obra en el campo. ${ }^{14}$

\footnotetext{
${ }^{14}$ Tampoco puede rechazarse la posibilidad de una interpretación diferente de las fluctuaciones en el ritmo del cambio distributivo en los años setenta y ochenta. Es posible que el rápido progreso distributivo observado en la segunda mitad de los setenta baya tenido un alto componente coyuntural, que no hubiera podido mantenerse en el tiempo. El aumento de los salarios rurales inducido por la bonanza cafetera y la recuperación de los salarios urbanos gracias a la desinflación de 1978 podrian haber hecho bajar el coeficiente Gini en más de un punto por encima de lo que podria esperarse de acuerdo con las tendencias de más largo plazo. Esta evolución coyuntural habria conducido a que las cifras del período 1971-1978 presentaran un progreso mayor inducido por las tendencias de largo plazo.
}

En el marco de esta dinámica de largo plazo, algunos fenómenos coyunturales e intervenciones de política que se dieron desde finales de los años ochenta afectaron el mercado de trabajo y las rentas no laborales.

Los acontecimientos que más influyeron en el mercado de trabajo fueron la enorme expulsión de trabajadores agrícolas y la reforma de la legislación laboral. La información disponible ${ }^{15}$ sugiere que durante el período 1988-1993 perdieron su empleo casi 400000 campesinos. De acuerdo con las encuestas de hogares, esta población no se quedó en la zona rural ni desocupada, sino que se emple 6 en las actividades urbanas. El empleo urbano registró durante este período un auge sin precedentes, duplicando el ritmo de creación de nuevos puestos de trabajo observado en la década de 1980. Pese al continuo aumento de las tasas de participación laboral, el desempleo urbano se redujo notoriamente entre 1986 y 1994 (de $16 \%$ a $8 \%$ ), eliminando todo el componente cíclico del desempleo que se generó en la primera mitad de los años ochenta. (López, 1995).

El prolongado auge de la construcción, el dinamismo de las exportaciones manufactureras y del comercio minorista de importaciones y la flexibilización de la legislación labora ${ }^{16}$ habrían desplazado la curva de demanda laboral para el conjunto urbano, produciendo mayor empleo sin reducir los salarios. Con esto, los salarios urbanos tendieron a crecer por encima de la inflación, especialmente en el período 1992-1994. Los mayores cambios se dieron en el mercado de trabajadores calificados. Ante la creciente escasez de oferta de capital humano, debida principalmente a la débil expansión de la educación secundaria desde fines de los años setenta, la mayor demanda parece haber elevado la rentabilidad de la educación y permitido un aumento apreciable de los salarios. La respuesta de la oferta ante cambios en la demanda parece haber sido más dinámica en el mercado no calificado. El examen de la información disponible sugiere que la afluencia de migrantes rurales a los centros urbanos parecería haber sido importante a comienzos de los años noventa, cuando en las ciudades había 500000 trabajadores sin educación y 1600000 trabajadores con educación primaria incompleta. ${ }^{17}$ Dado que éste

\footnotetext{
${ }^{15}$ Proveniente de las encuestas de hogares analizadas (EH 73, EH77, EH81 y Encuesta CASEM), así como de Reyes, 1995.

${ }^{16}$ Según Lora y Henao (1995), la reforma laboral genero un cambio estructural, desplazando la demanda laboral en la industria manufacturera de una forma tal que habría generado $30 \%$ más empleo que bajo la vieja legislación.

${ }^{17}$ Encuesta de Hogares EH73 de septiembre de 1991.
} 
es precisamente el prototipo de educación de los trabajadores agrícolas, la llegada a la ciudad de 400000 de estos trabajadores seguramente generó abundancia de mano de obra no calificada, que habría hecho posible prolongar la expansión del empleo sin presionar los salarios al alza. En las ciudades, la combinación de escasez de oferta de trabajo calificado y abundancia de mano de obra con poca instrucción se habría manifestado en un aparente aumento de la rentabilidad de la educación. ${ }^{18}$ Por ello hubo un inesperado retroceso en la disminución de la desigualdad laboral que la economía colombiana había venido exhibiendo continuamente desde finales del decenio de $1960 .^{19}$

Los mercados de capital también experimentaron enormes cambios en los años noventa. La tendencia a la reducción de la rentabilidad del capital que se registr6 sostenidamente desde la posguerra se aceleró con las entradas de capital externo. Las rentas monopolicas de los mercados de productos agrícolas y manufactureros se habrían aminorado con la creciente competencia de productos externos originada por la apertura económica. Según la información disponible, con estos acontecimientos se habría acelerado la reducción de la desigualdad en las ganancias de las familias urbanas que se venía observando en las últimas décadas, y también se habría revertido el aumento de la desigualdad de las rentas agrícolas ${ }^{20}$ que se había prolongado durante las dos décadas anteriores. Paradojicamente, la crisis agrícola de comienzos de los años noventa, en un contexto de movilidad de los factores, hizo que el menor crecimiento del ingreso nominal afectara principalmente a los dueños de la tierra con lo cual la distribución del ingreso agrícola habría mejorado. 21

${ }^{38}$ Como lo señalan Tenjo (1993), Berry y Tenjo (1995) y Robbins (1995).

${ }^{19}$ Esta creciente desigualdad de los ingresos laborales urbanos en el periodo reciente ha sido identificada, entre otros, por Tenjo (1993), Berry (1995a), Altimir (1996) y Sánchez (1996).

${ }^{20} \mathrm{La}$ tendencia a la reducción de la desigualdad de las rentas rurales que figura en la encuesta CASEM aparece confirmada con los resultados de la Encuesta Nacional de Hogares $\mathbf{8 1}$ que el DANE realizó casi simultáneamente.

21 Para algunos analistas (Lora y Steinet, 1995; Banco Mundial, 1994; DNP, 1995) la ampliación de la diferencia entre los ingresos rurales y urbanos fue la principal fuente de deterioro distributivo en los años noventa. En efecto, si la distribución de la población urbano-rural hubiera permanecido estable, los cambios en la relación de precios del término de intercambio entre la agricultura y el resto de ta economía habrían producido menores ingresos relativos por trabajador (o por familia) agrícola. Pero si la población es móvil, la relación unívoca entre los movimientos del valor agregado y los ingresos relativos se rompe. Tal sería el caso durante este período, cuando la migración de trabajadores agrícolas habría sido de tal magnitud que la brecha de productividad por trabajador entre la agricultura y las actividades urbanas, en lugar de ampliarse, se habría cerrado entre 1988 y 1993.
CUADRO 3

Colombia: Indices de desigualdad, 1978-1993

\begin{tabular}{lccc}
\hline & 1978 & 1988 & 1993 \\
\hline Ingresos laborales & 0.411 & 0.402 & 0.449 \\
$\quad$ De asalariados urbanos & 0.382 & 0.352 & 0.385 \\
$\quad$ De otros trabajadores & 0.458 & $\mathbf{0 . 4 7 5}$ & 0.478 \\
Ingresos no laborales & 0.564 & 0.571 & 0.514 \\
Total & 0.481 & 0.476 & 0.472 \\
\hline
\end{tabular}

Las tendencias estructurales y algunos hechos coyunturales generaron tensiones contradictorias en la distribución del ingreso: el ingreso factorial de las familias se distribuyó hacia el trabajo, la dispersión disminuyó para los ingresos no laborales pero aumentó para los ingresos del trabajo. Los dos primeros efectos resultaron cuantitativamente más importantes que el tercero. Por ello, la distribución del ingreso mejoró en la primera mitad de los años noventa (cuadro 3). ${ }^{22}$

\section{Los cambios distributivos en una visión com- parativa}

La distribución del ingreso en Colombia en los años setenta y ochenta no ha permanecido estática en los niveles del decenio de 1960 con los que fue conocida internacionalmente. Como se vio en las secciones anteriores, después de un prolongado período de deterioro que toc 6 fondo a fines de ese decenio, la distribución del ingreso ha mejorado continuamente en los veinticinco años siguientes, más rápidamente en los años setenta, más lento en los ochenta y con una aceleración parcial en la primera fase de los noventa.

¿Cómo juzgar cuán significativos fueron los njveles y los cambios en la desigualdad colombiana durante este período? Una forma simple es comparar la evolución del coeficiente Gini en Colombia con lo que ocurriría en un país típico que tuviese la evolución prevista por Kuznets, ${ }^{23}$ o con lo que ocurrió en Inglaterra en los últimos años (Williamson, 1985). Para hacer más simple la comparación, se normalizó el PIB en términos de años equivalentes de crecimiento (al $1.8 \%$ anual). Las variaciones previstas por Kuznets nor-

\footnotetext{
${ }^{22}$ Los análisis de Berry (1995a), Altimir (1994) o L. Sarmiento (1995), que se concentran en la distribución del ingreso laboral urbano, entregan una visión incompleta de los cambios distributivos en el conjunto de la sociedad.

${ }^{23}$ Se utiliza una regresión de la forma Gini $=a+b \ln (Y)+c \ln 2$ (Y), siendo $\mathrm{Y}$ el ingreso per cápita con poder adquisitivo comparable (PPP) a precios de 1980 y In su logaritmo natural. Se utilizaron 143 observaciones para 93 países durante el período 1958-1983, como indica Londoño (1995b).
} 
malmente toman mucho tiempo en desarrollarse (gráfico 6). Un aumento de la desigualdad como el que mostró Colombia en los años sesenta $\rightarrow$ de 10 puntos en el coeficiente Gini- normalmente tomaría 100 o 150 años en un país promedio. Y la disminución en la desigualdad colombiana en los 25 años considerados se observaría en otros países en un plazo tres o cuatro veces más largo.

Frente a estos patrones típicos, la experiencia inglesa parece haber sido de cambios distributivos extremos. Colombia ha mostrado cambios distributivos de similar magnitud que los ingleses (y la desigualdad colombiana en los años sesenta no era muy diferente de la inglesa 100 años atrás), pero en un plazo muchísimo menor. Así, lo que tomó a Inglaterra más de 250 años, Colombia lo vivió en el breve plazo de 50 años.
GRAFICO 6

Reino Unido y Colombia: Curva de Kuznets

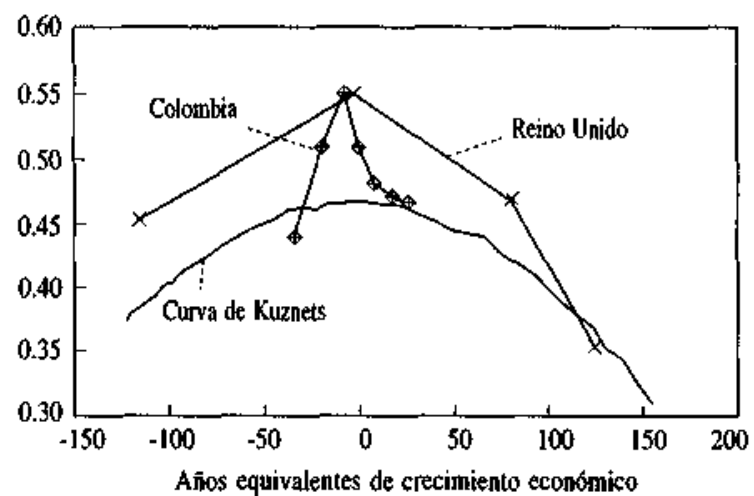

(al $1.8 \%$ anual)

Fuente: Londoîo, 1995 b.

\section{IV}

\section{Los efectos de la política social: la redistribución secundaria del ingreso}

En el caso de Colombia, la llamada segunda ronda distributiva se ha vuelto cada vez más importante, especialmente a partir de la década de 1980. Las transferencias externas y del sector público ${ }^{24}$ hacia los hogares colombianos y las transferencias de renta de las empresas colombianas al exterior han crecido considerablemente. Hacia 1993 cada una de estas fuentes era, como proporción del PIB, tres veces más importante que a comienzos de los años setenta (gráfico 7), lo que amerita un examen más detallado del efecto redistributivo entre los hogares que tiene el sector público. ${ }^{25}$

\section{La evolución del gasto social}

El gasto público social per cápita crecí́ entre 1970 y 1995 al $4.0 \%$ anual en términos reales. ${ }^{26}$ En la diná-

\footnotetext{
${ }^{24}$ Se definen como la diferencia entre la suma de los impuestos y contribuciones de los hogares y el gasto social recibido por ellos. ${ }^{25}$ Las transferencias de renta de la propiedad al exterior parecen tener poco impacto directo sobre el ingreso de los hogares, toda vez que provienen fundamentalmente de las ganancias retenidas por las empresas del sector minero. En cambio la importancia de las transferencias directas del exterior a los hogares colombianos ha crecido como resultado de las remesas de los colombianos que viven en el exterior y de las nentas del narcotrafico. Dada la poca información disponible al respecto, no es posible analizar el efecto de estas últimas transferencias sobre la distribución del ingreso.
}

GRAFICO 7

Colombla: La segunde ronda redistributiva

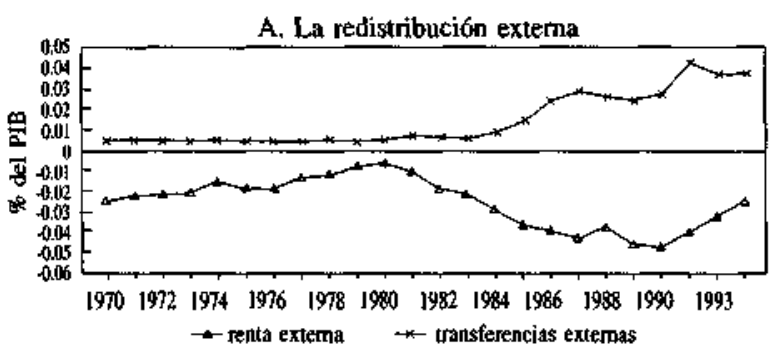

B. La redistribución póblica ${ }^{\mathrm{a}}$

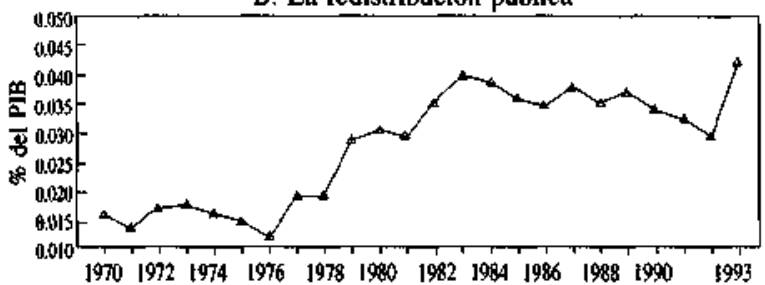

- La redistribución pública es la diferencia entre el gasto social por un lado. y los impuestos y contribuciones pagados por los hogares, por otro.

${ }^{26}$ Para evaluar el gasto público social se ha utilizado una fuente de información plenamente consistente, poco utilizada por los analistas colombianos: el cuadro 30 de las Cuentas Nacionales del DANE, de clasificación de los gastos de las administraciones públicas por finalidad y objeto económico. Los datos de 1994 y 1995 los obtuve por extrapolación, sobre la base de la información contenida en Sánchez, 1996. Se incluye en el gasto social los gastos en salud y sanidad, educación y capacitación, asistencia social y seguridad social (tanto en pensiones como en salud); en este último caso se incluyen los gastos en salud y pensiones de las empresas públicas. 
GRAFICO 8

Colombia: Evolución del gasto público social, 1970-1995

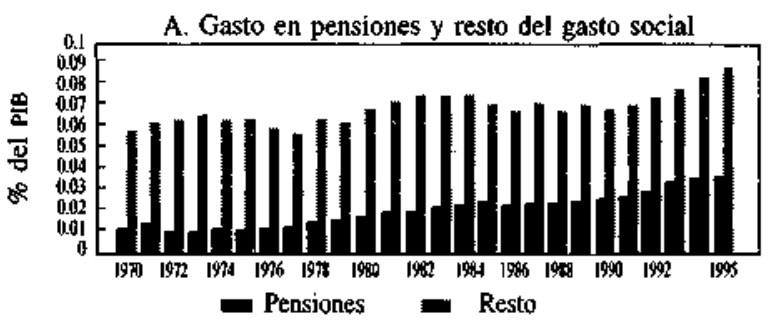

B. Gasto por sextores

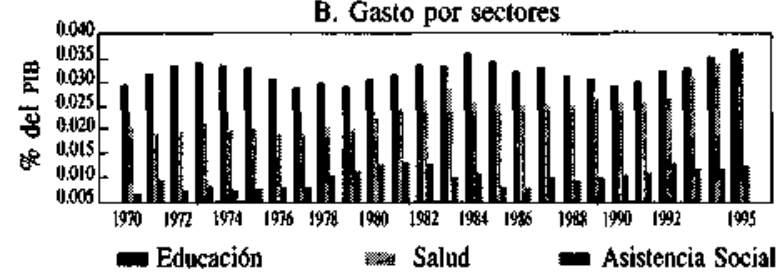

mica de este gasto público pueden distinguirse dos componentes (gráfico 8). El primero es el gasto en pensiones, que en términos per cápita ha crecido en $7.4 \%$ por año, en forma rápida y relativamente estable, y que entre 1970 y 1995 elevó su participación en el PIB de $1.0 \%$ a $3.7 \%$. El segundo es el resto del gasto social, que ha aumentado con menor rapidez $-3.2 \%$ anual per cápita- y en medio de claros ciclos. A su vez estos ciclos, como lo ilustra la sección B del gráfico, se han originado principalmente en el gasto en educación, que ha fluctuado enormemente sin tendencia muy definida. Los gastos en salud, en cambio, han oscilado menos y aumentaron considerablemente su participación en el PIB entre 1993 y 1995.

En conjunto, el gasto público social prácticamente se dobló como proporción del PIB entre 1970 y 1995 (pasó de $6.7 \%$ a $12.5 \%$ ), y se financió crecientemente con recursos que no provinieron de los hogares (gráfi$\operatorname{co} 7$, sección B).

\section{El efecto distributivo del gasto social}

Además de información detallada sobre la evolución del gasto social entre 1970 y 1995, Colombia cuenta con dos estudios de altísima calidad sobre la distribución de los beneficios del gasto público entre sus usuarios. El estudio pionero fue realizado por Selowsky (1979) con información de mediados de los setenta. Posteriormente Vélez (1996) replicó la metodología con información de comienzos de los noventa. La comparación de ambos estudios permite estimar los niveles y cambios en la redistribución del ingreso que se realiza a través del sector público.
El impacto del gasto social sobre la distribución del ingreso depende de su monto, de la forma como se financia y de la manera como se distribuyen sus beneficios entre los usuarios. Estos resultados pueden expresarse matemáticamente en la siguiente ecuación, ${ }^{27}$ que descompone el coeficiente Gini en términos de los coeficientes de concentración (C) y progresividad (P) de los distintos tipos de impuestos y subsidios:

$$
\Delta G=G f-G o \stackrel{\gamma(C s-G o)-\tau(C t-G o)}{l+\gamma-\tau} \frac{\gamma P s-\tau P}{1+\gamma-\tau^{28}}
$$

donde:

$$
\gamma=\frac{S}{Y_{o}}, \quad \tau=\frac{T}{Y o}
$$

son las fracciones del ingreso representadas por subsidios e impuestos y

$P s=C s-G o, P t=C t-G o$ son los coeficientes de progresividad de los subsidios e impuestos.

Es decir, los cambios en los coeficientes Gini pueden descomponerse en términos de las fluctuaciones en la progresividad de los diferentes subsidios e impuestos (medidos por los coeficientes de concentración o por los de progresividad) y de los cambios en la magnitud cuantitativa de tales subsidios e impuestos.

Entre 1975 y 1995 el gasto público en educación y salud se tornó más progresivo en Colombia. Los coeficientes de concentración del gasto en educación y salud ${ }^{29}$ se hicieron más negativos, lo que indica que él llego en mayor proporción a los estratos más pobres (cuadro 4). Donde hubo un progreso espectacular fue en la educación: en el período Colombia pasó de uno de los índices más regresivos de América Latina a uno que supera al de los parses del cono sur del continente. ${ }^{30}$ En los gastos de salud la progresividad fue mayor, aunque su incremento fue más lento en el período $1970-1992 .{ }^{31}$

\footnotetext{
${ }^{27}$ Derivada por Vélez y Medina (1995) sobre la base de Kakwani, 1977.

${ }^{28} \mathrm{Go}=$ Coeficiente Gini antes de los subsidios

$\mathrm{Gf}=$ Coeficiente Gini después de los subsidios

$\mathrm{C}=$ Coeficiente de concentracion

$\mathrm{P}=$ Coeficiente de progresividad

$s=$ subsidios

$\mathrm{t}=$ impuestos.

${ }^{29}$ No hay información que permita realizar un análisis similar para las transferencias implícitas en el sistema de pensiones.

${ }^{30}$ Según CEPaL (1995), el coeficiente Gini del gasto en educación de Colombia en 1992 fue de -0.17. El mismo coeficiente en Argentina era de -0.10 , en Chile de -0.12 y en Uruguay de -0.18 , de modo que el de Colombia se compara favorablemente con ellos.

${ }^{31}$ Una vez que se implemente completamente el régimen subsidiado de la ley 100 y funcione a cabalidad el régimen de contribuciones, el sistema de salud podría resultar mucho más progresivo que la educación primaria. Cálculos preliminares indican que la reforma de salud podría contribuir en sus primeros cinco años de funcionamiento por lo menos con 2 puntos adicionales de reducción del coeficiente Gini.
} 
CUADRO 4

Colombia: Progresividad del gasto soclal

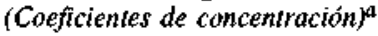

\begin{tabular}{lcc}
\hline & 1974 & 1992 \\
\hline Educación & 0.006 & -0.081 \\
Primaria & -0.256 & -0.347 \\
Secundaria & 0.001 & -0.124 \\
$\quad$ Universitaria & 0.551 & 0.325 \\
Salud & -0.143 & -0.159 \\
$\quad$ Ministerio de Salud & -0.143 & -0.66 \\
Seguridad Social & 0.156 & 0.218 \\
Total & & -0.013 \\
\hline
\end{tabular}

Fuente: Selowsky (1979) y Vélez (1996).

a El coeficiente de concentración varía entre -1 y +1 . Si es positivo, es regresivo.

El impacto del gasto público en educación y salud sobre la distribución del ingreso de los hogares depende de la magnitud relativa de las transferencias por gasto social y de la evolución de su progresividad. En el marco de los parámetros de la sociedad colombiana, resultó ser de enorme importancia. Para evaluarlo entre 1970 y 1995 se realizaron dos simulaciones. En la primera se evaluó el efecto del esfuerzo de gasto social en los diferentes sectores, considerando fijos los coeficientes de progresividad de sus servicios. ${ }^{32}$ En la segunda se evaluó el efecto de la progresividad del gasto en los diferentes servicios sociales, de acuerdo con la evolución observada en el período. ${ }^{33}$

El ejercicio dio dos resultados importantes (gráfico 9). Gracias a la redistribución del ingreso genera- da por el gasto social, el coeficiente Gini se redujo 3.7 puntos, lo que es el equivalente a muchas décadas de crecimiento económico. El efecto redistributivo fue de 2.1 puntos del Gini en 1970 y de 3.7 en 1995, por lo que puede decirse que la evolución del gasto social en esos 25 años contribuyó a reducir en 1.6 puntos el coeficiente Gini. Como se observa en el gráfico, la mitad de este efecto provino de los cambios en la magnitud y composición del gasto social entre los distintos servicios. La otra mitad del efecto (la diferencia entre las dos líneas en el gráfico) se logró por la mejor focalización del gasto social en cada uno de los sectores, especialmente durante los últimos dos gobiernos.

GRAFICO 9

Colombia: Efecto distributivo del gasto social

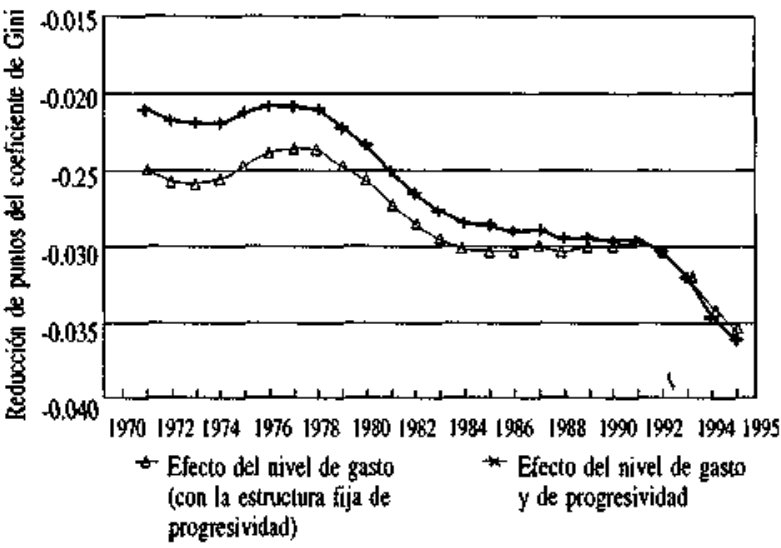

\section{V}

\section{La evaluación global de las tendencias}

\section{distributivas}

Como se ha visto en las secciones anteriores, la distribución del ingreso final de los individuos puede modificarse si cambia la distribución del ingreso primario de la economía, o si la acción pública la afecta,

\footnotetext{
${ }^{32}$ Se utilizaron los coeficientes de 1992 presentados en Vélez (1996). ${ }^{33}$ Ante la falta de información más detallada, los coeficientes se extrapolaron linealmente entre 1974 y 1992.
}

a través de transferencias ${ }^{34} \mathrm{e}$ impuestos. La importancia de cada uno de estos mecanismos distributivos se ha ilustrado en las dos secciones anteriores. Esta sección se propone integrar los resultados de ambas para

\footnotetext{
${ }^{34}$ En este artículo sólo se consideran tos efectos distributivos del gasto público social. Vélez (1996) realiza el análisis completo del impacto del resto del gasto público -especialmente en las empresas de servicios públicos-y de los impuestos.
} 
observar en conjunto las tendencias distributivas entre 1970 y 1995.

Como vimos en la sección III, en esos 25 años la distribución primaria del ingreso tuvo dos fases: progreso rápido hasta comienzos de los ochenta, $\mathrm{y}$ desde entonces progreso más lento, con alguna aceleración en los noventa. Entre 1971 y 1993, el coeficiente Gini se redujo en 5.3 puntos, es decir a una tasa media de 0.21 puntos por año; la tasa aproximada de reducción anual fue de 0.47 puntos anuales en los años setenta, de 0.05 puntos en los ochenta y de 0.10 puntos en los noventa. Por su parte, la redistribución secundaria del ingreso a través del gasto social tuvo una dinámica temporal bastante diferente. En los años setenta ese gasto creció con más lentitud que el ingreso de las familias y no hubo ningún efecto distributivo neto. A comienzos del decenio de 1980 se incrementó, generando mejoras redistributivas, pero dejó de hacerlo a partir de 1984 y por lo menos hasta 1991. En 19921995 aumentó más rápido que el ingreso de las familias, y como a la vez mejoró la focalización de los recursos hacia los más pobres, el efecto distributivo se aceleró notoriamente.

La conjunción de tales cambios en la distribución primaria y secundaria define dos fases distintas en las tendencias distributivas de 1970-1995 (gráfico 10). La distribución final del ingreso mejoró más rápidamente en los años setenta, sobre todo merced a la dinámica de los mercados laborales; pero luego el ritmo del avance bajó a menos de la mitad del anterior, porqque a pesar de que la redistribución físcal se aceleró, las fuentes de cambio distributivo primario perdieron su dinamismo.

¿Cómo se compara entonces la trayectoria de la distribución del ingreso efectivo en Colombia con los patrones internacionales durante los 25 años considerados? Un ejercicio empírico indica que, gracias al efecto del rápido progreso en la distribución del ingreso monetario en los años setenta, y al enorme impacto distributivo del gasto social en los noventa, el grado de desigualdad del ingreso efectivo en Colombia ya no es mayor que lo que cabría esperar conforme a los patrones internacionales (gráfico 11). En efecto, el descenso de la desigualdad del ingreso primario en el decenio de 1970 fue rápido, pero no alcanzó a eliminar el exceso de desigualdad que había acumulado Colombia hasta los años sesenta. En seguida el avance se hizo lento, y a tal ritmo la convergencia a los niveles de desigualdad predichos por Kuznets para
GRAFICO 10

Colombla: Fuentes de progreso distributivo

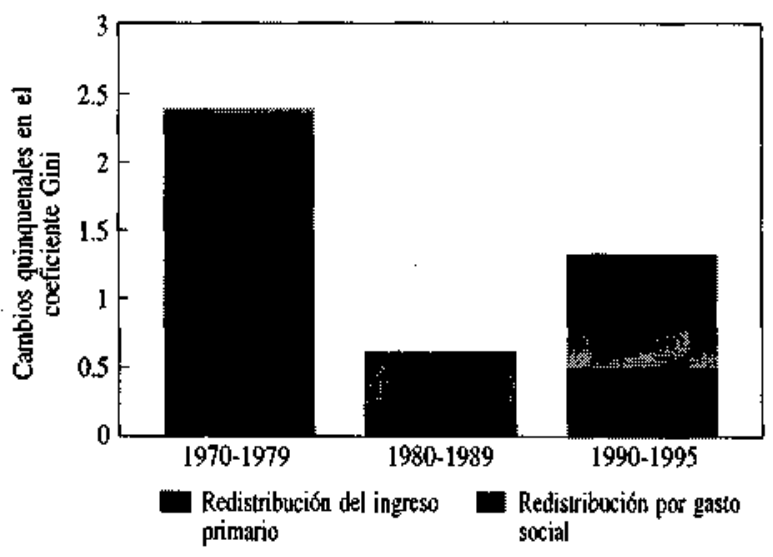

GRAFICO It

Colombla: Patrones distributivos y gasto sociala

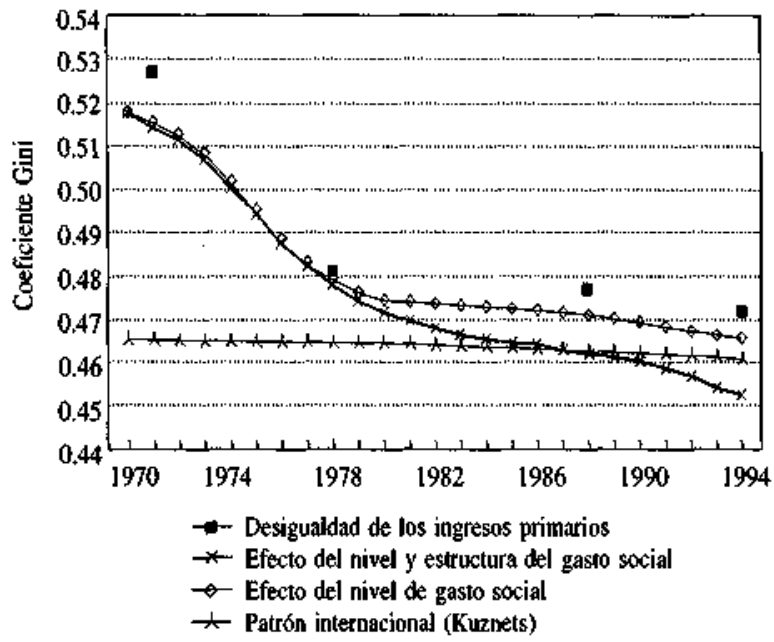

" Todos los datos tienen promedios móviles de 5 años centrados.

países de desarrollo similar habría de tomar varias décadas más. Pero el gasto social se dinamizó en los años siguientes. Si la expansión de ese gasto se hubiera dado sin cambiar la estructura del sector público que había en los años setenta, no habría alcanzado a eliminar el exceso de desigualdad. Pero la creciente equidad del gasto público social desde los años ochenta, unida a su crecimiento dinámico en los noventa, aceleró la disminución de la desigualdad que Colombia había mantenido por 50 años. 


\section{VI}

\section{Tendencias de la pobreza y los indicadores de}

\section{desarrollo humano}

Los índices de desigualdad en Colombia son aún altos para cualquier observador. Pero como vimos en las secciones anteriores, la desigualdad disminuyó persistentemente en 1970-1995, y gracias a la expansión y focalización del gasto social ya no se encuentra por encima de los patrones internacionales. Sin embargo, los cambios lentos en los niveles de desigualdad podrían ir paralelos con un ritmo también muy lento de superación de la pobreza o de mejora de los indicadores de bienestar. ¿Habrá sido éste el caso colombiano? En esta sección se describen las tendencias de la pobreza y de los indicadores básicos de salud y educación en el período indicado.

\section{Las tendencias de la pobreza}

Las mediciones de la pobreza a lo largo del tiempo han suscitado tantos debates metodológicos como las mediciones de la distribución del ingreso. La metodología preferida determina el porcentaje de la población que por su ingreso monetario insuficiente se encontraría por debajo de una línea de pobreza. Desde el punto de vista del bienestar, sin embargo, no es evidente que la falta de ingreso monetario exprese todas las carencias de la población (Sen, 1992), especialmente cuando un componente importante del consumo no pasa por el mercado (como ocurre con la producción para el autoconsumo o el consumo de bienes provistos por el sector público). Tampoco está fuera de debate la construcción precisa de los umbrales a partir de los cuales la gente pueda o no ser considerada pobre. ${ }^{35}$ En los últimos años se ha generalizado en América Latina otro criterio para medir la pobreza: el de las necesidades básicas insatisfechas, como las de empleo, educación, vivienda y servicios básicos (PNUD, 1989). También se ha debatido largamente cuáles bienes deben incluirse en la canasta de bienes básicos, y aún dista de haber consenso al respecto entre los analistas. En lo que sí hay un creciente acuerdo es en que ambos indicadores sólo captan parcialmente la

${ }^{35}$ Véase en CEPAL (1991) un buen análisis de los problemas empiricos que surgen en la construcción de estas líneas de pobreza. compleja dimensión del problema de la pobreza. ${ }^{36}$ (Gráfico 12).

La información disponible en Colombia permite cuantificar la evolución de la pobreza en períodos relativamente largos de tiempo. Si se examina la dinámica de la población bajo la línea de pobreza o con necesidades básicas insatisfechas entre 1970 y 1995 , vemos que en los años setenta disminuyó más rápidamente la población considerada pobre por este último criterio, y que en los años ochenta esa disminución se desaceleró (las personas que anualmente dejaban de ser pobres por este concepto bajaron de 200000 en la década anterior a 180000 , es decir, del 2.0 al $1.2 \%$ de la población). La tasa de pobreza por insuficiente ingreso monetario (línea de pobreza) prácticamente no cambió, con lo cual el número absoluto de personas con ingreso insuficiente aumentó considerablemente. En la primera mitad de los años noventa la reducción de la pobreza se aceleró, tanto en términos absolutos como relativos, conforme a uno u otro criterio. Medida por las necesidades básicas insatisfechas, la pobreza se redujo entre 1990 y 1994 en 900000 personas por año ( $3.1 \%$ de la población), más que triplicando lo logrado en los años ochenta. ${ }^{37}$ Medida por el ingreso monetario insuficiente, se redujo a ritmo más lento, pero en todo caso cuatro veces más rápido que en los años ochenta ( $0.8 \%$ contra $0.2 \%$ anual). Esto permi-

\footnotetext{
${ }^{36}$ Existen interesantes estudios analíticos y empíricos que proponen mediciones alternativas. Boltvinik (1992) ha propuesto, basándose en Kaztman (1989), una medición integrada de la pobreza (Mis), combinando en una matriz las poblaciones clasificadas como pobres bajo una u otra metodología. Castafieda (1992) ha desarrollado un sistema de identificación de población pobre (SISBEN) basado en un conjunto más amplio de indicadores de ingreso y consumo de bienes privados y públicos.

${ }^{37}$ La Revolución Pacífica -el plan de desarrollo del gobierno de Gaviria - se propuso como meta reducir la pobreza, medida por las necesidades básicas insatisfechas, del $39.5 \%$ al $27.3 \%$ de la población entre 1990 y 1994, con sus estrategias de aumento del empleo a través de la aceleración del crecimiento economico, la vivienda, el agua potable y la educación (Colombia, DNP, 1991, p. XX). La Encuesta Nacional de Hogares de septiembre de 1994 encontró que el $27.1 \%$ de la población se hallaba en la pobreza por necesidades básicas insatisfechas de modo que, contrario a la percepción de muchos críticos, la principal meta de La Revolución Pacífica se logro más que satisfactoriamente.
} 
GRAFICO 12

Colombia: Población pobre definlda según su ingreso y sus necesidades básicas insatisfechas (NBI)
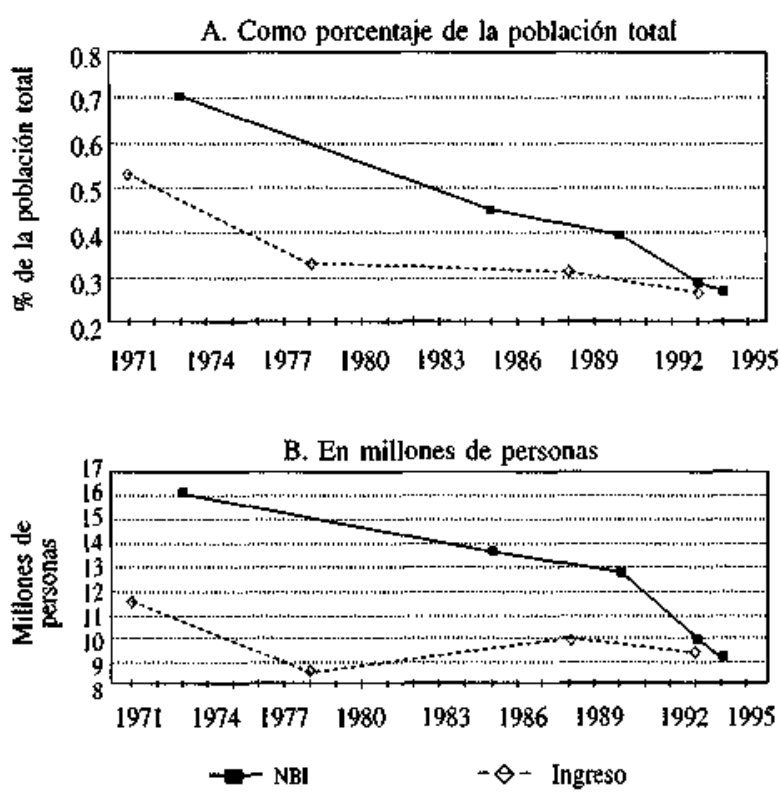

Fuente: Cálculos del autor, basados en datos del DANE.

tió revertir el aumento del número de personas con ingreso monetario insuficiente registrado en la década anterior. ${ }^{38}$

Así, la pobreza en Colombia tendió a disminuir rápidamente entre 1970 y 1995 , con mayor velocidad en los noventa. Si el grado de desigualdad del ingreso en Colombia ya no resulta sorprendente en términos internacionales, el nivel de pobreza por falta de ingreso monetario tampoco parece estar por encima de lo que se esperaría de acuerdo con la experiencia de otros países de nivel similar. Esto contrasta marcadamente con la situación del resto de América Latina, donde la proporción de personas pobres aumentó sostenidamente en el decenio de 1980 , y el número de pobres por ingreso monetario insuficiente pasó de 120 millones a 168 millones entre 1980 y en $1995 .^{39}$

\section{Las tendenclas de los indicadores de desarro- llo humano}

Los análisis recientes del desarrollo humano (PNUD, 1995) han privilegiado la medición del bienestar hu-

\footnotetext{
${ }^{38}$ Los datos más recientes indican que la desaceleración de la economía a partir del segundo semestre de 1995 habría estado acompañada por aumentos en la tasa de pobreza y el número de pobres. ${ }^{39}$ Véase un análisis de estas tendencias en Londoño, 1996b.
}

GRAFICO 13

$$
\begin{aligned}
& \text { Colombla: La evolución de ta mortalidad } \\
& \text { infantila }
\end{aligned}
$$

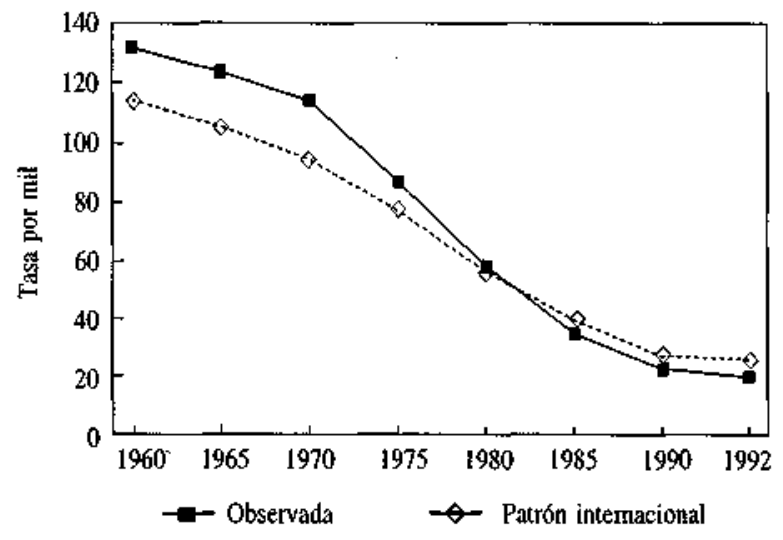

"Menores de cinco años.

mano por un conjunto básico de indicadores de la salud y la educación de la población: la mortalidad infantil, ${ }^{40}$ las esperanzas de vida al nacer y la escolaridad media de la población en edad de trabajar. Para completar el examen del bienestar humano y su evolución en Colombia compararemos la trayectoria de cada indicador con la que cabría esperar para el país por su grado de desarrollo y las tendencias internacionales. ${ }^{41}$

La mortalidad infantil en Colombia se ha reducido con particular rapidez en las últimas décadas (gráfico 13). En los años sesenta era $15 \%$ más alta que los patrones internacionales, y la diferencia tendió a ampliarse hasta comienzos de los setenta; de allí en adelante se redujo más rápidamente que en el promedio de países con similar desarrollo, y desde mediados de los ochenta ha sido casi $25 \%$ menor que la esperada internacionalmente para tales países. La evolución de la desigualdad y del gasto en salud pública

\footnotetext{
${ }^{40}$ Se refiere a la mortalidad antes del quinto año, medida por encuestas directas (Hill y Pande 1996).

4l El análisis comparativo parte de la base de datos del Banco Mundial sobre ingreso per cápita (a poder adquisitivo internacional), expectativas de vida, mortalidad en la niñez y educación de la fuerza de trabajo para más de 100 países durante el período 1950 1992. El cálculo del patrón internacional se hizo mediante la siguiente regresión:

$\ln (I D H)=a+b \ln (y)+c \ln 2(y)+d$ Region.it e Time.t donde el logaritmo natural de cada indicador de desarrollo humano (10H) se regresó en función del ingreso per ć́pita y su cuadrado, y variables ficticias que captan cada una de las nueve regiones del mundo y cada uno de los quinquenios de la posguerra.
} 
GRAFICOO 14

Colombia: Evolución observada y esperada de las esperenzas de vida y de la educación, 1950-1990

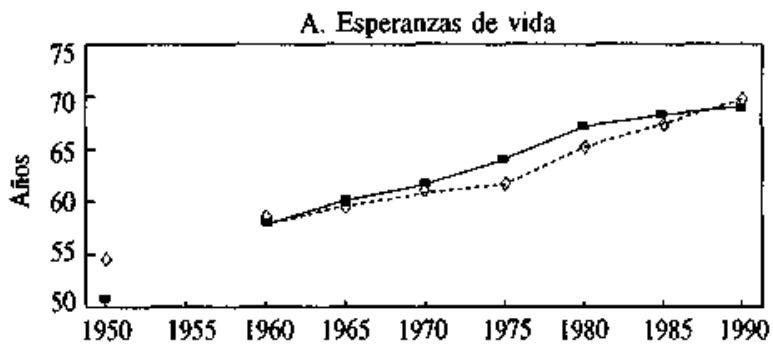

B. Educación

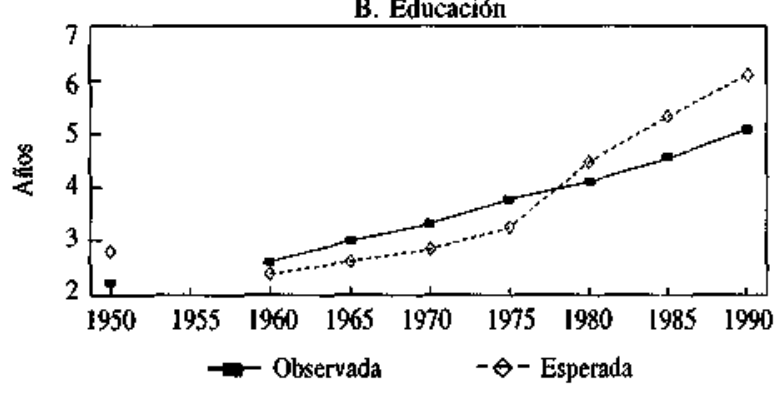

durante los diferentes períodos vividos por Colombia podría explicar este resultado.

De otro lado, la comparación de las esperanzas de vida y la escolaridad de la fuerza de trabajo de Colombia con los patrones internacionales genera otras sorpresas.

Según varios estudios recientes, las esperanzas de vida resultan bastante elásticas al ingreso y a la difusión de la tecnología médica (Banco Mundial, 1993). Tienden a elevarse aceleradamente en países con ingresos medios como los que tuvo Colombia en los años cincuenta y sesenta; pero cuando se acercan a los 70 años tienden a ascender más lentamente. Las esperanzas de vida en Colombia (grafico 14, sección A) eran anómalamente bajas en los años cincuenta, pero en los decenios de 1960 y 1970 se elevaron con más rapidez que en el promedio de países de similar desarrollo; a partir de 1985 ascendieron muy lentamente, pese a que se aceleró la reducción de la mortalidad infantil. La explicación parece simple: el aumento de la tasa de homicidios en la población joven habría conducido a que las esperanzas de vida de la población masculina no crecieran en los últimos diez años. ${ }^{42}$

\footnotetext{
${ }^{42}$ Esta situación ha sido debidamente analizada en Galvis (1989) y Colombia, Ministerio de Salud (1994).
}

GRAFICO 15

Colombia: Evolución de la mortalidad infantila y las esperanzas de vida, $1950-1990^{\mathrm{b}}$
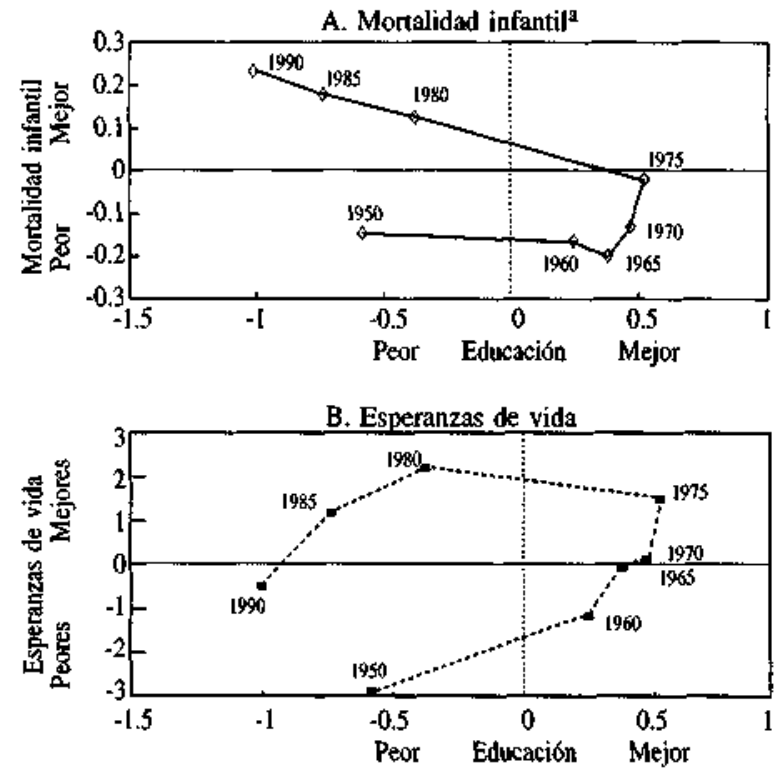

a Menores de cinco años.

b Las diferencias se miden en affos.

La educación de la fuerza de trabajo colombiana era particularmente baja para el nivel de desarrollo que tenía el país en los años cincuenta (gráfico 14, sección B). Pero la rápida expansión de la enseñanza primaria desde finales de los años cincuenta hasta mediados de los setenta permitió que Colombia alcanzara niveles de educación superiores a los esperados. Sin embargo, desde fines de los años setenta coincidieron una baja del ritmo de acumulación de capital humano y una aceleración esperada en las expectativas de educación vinculadas al desarrollo logrado. Así, en la década de 1980 Colombia exhibió un rezago educativo creciente frente a los patrones internacionales, que no da seña de reducirse en la década de $19900^{43}$

$\mathrm{El}$ análisis combinado de los tres indicadores de desarrollo humano señalados nos permite describir la evolución de las brechas sociales en Colombia en 1950-1990 (gráfico 15). En los años cincuenta, el país mostraba menores logros en salud infantil y educación

\footnotetext{
${ }^{43}$ En 1990-1994 el gobiemo de Gaviria buscó acelerar la expansión de la matrícula en educación secundaria. La cobertura se elevo del $50 \%$ al $56 \%$ de la población en la edad pertinente (Calderón, 1996). Este resultado, aunque positivo, no alcanzó a contrarrestar las crecientes demandas de educación impulsadas por el patrón de desatrollo colombiano en el nuevo contexto internacional.
} 
de los jovenes que países similares. En los años sesenta se mantuvo la insatisfactoria situación en salud infantil, pero el esfuerzo educativo resultó muy exitoso. A partir de los años ochenta la salud infantil progresó más que satisfactoriamente, en tanto que la educación se rezagó notablemente en comparación con lo esperado en el resto del mundo. Los logros en materia de mortalidad infantil fueron contrarrestados en ocasiones por el impacto de la violencia (gráfico 15, sección B). En los años sesenta y setenta la aminoración de la violen- cia permitió que las esperanzas de vida mejoraran más rápidamente que lo que decreció la mortalidad infantit. Pero en la década de 1980 ocurrió lo contrario, con lo cual se habría dado toda la vuelta al círculo. Colombia, después de haber sobresalido internacionalmente por su nivel educativo en los años setenta y por sus esperanzas de vida al comienzo de los ochenta, se encontraría a mediados de los noventa, una vez más, en condiciones de educación y de expectativas de vida por debajo de las esperadas para su nivel de desarrollo.

\section{VII}

\section{Las perspectivas sociales en Colombia:}

\section{algunas reflexiones}

Las secciones anteriores brindan una descripción simple pero coherente de la evolución de los principales problemas sociales que enfrenta Colombia. Como se vio, y contrario a las expectativas de muchos críticos, la sociedad colombiana de los años noventa no presenta creciente desigualdad ni mayor pobreza debidas a la combinación de supuestas tendencias estructurales inevitables o al efecto de políticas neoliberales. Las reformas comerciales y laborales, en medio de una política de gasto social expansiva pero sanamente financiada y crecientemente focalizada en la población más pobre, permitieron acelerar el progreso en la distribución del ingreso efectivo en la población. El grado de desigualdad y pobreza en Colombia, aunque es alto y constituye un problema social doloroso, ha dejado de sorprender en comparaciones internacionales.

No obstante, el avance reciente, aunque es un hecho positivo, no parece necesariamente sostenible en el futuro. El avance distributivo en el decenio de 1980 se logró en gran medida con gasto social que compensaba a la población más pobre por lo que los mercados laborales le negaban en forma espontánea, y con la reducción de la desigualdad de los ingresos no laborales. Los factores que en el pasado contribuyeron en mayor medida a impulsar la equidad, y que podrían hacerlo hoy, continúan debilitándose.

Particularmente preocupante es el lento desarrollo del capital humano colombiano. El país sigue quedándose innecesariamente corto en la prioridad que concede a la educación y la formación para el trabajo, y va cada vez más a la zaga de los patrones internacionales. Los acontecimientos de los últimos años in- dican que la restricción de capital humano podría ser más importante que lo que pensaron la mayor parte de los analistas y políticos colombianos.

El ritmo de crecimiento de la inversión agrícola, especialmente en mejoramiento de tierras, también está siendo muy lento. Si no se refuerzan las bases para asegurar un crecimiento anual muy superior al de 1980 . 1995 el avance económico puede no estar a la altura de las expectativas de la población.

De otra parte, han comenzado a ganar importancia fuentes de ingresos que podrían contrarrestar las tendencias recientes a mejorar la equidad. Las rentas cada vez mayores del narcotráfico han terminado por tener efectos considerables sobre la propiedad de los activos urbanos y rurales (Pardo, 1996), que tarde o temprano podrían generar mayor desigualdad. Las rentas provenientes de las actividades criminales - la guerrilla y la violencia común - son una forma de redistribución cada vez más regresiva. Y la ascendente concentración del excedente en las rentas mineras puede terminar manifestándose en una creciente desigualdad de los ingresos de los hogares.

A la vez, la posibilidad de prolongar en el tiempo la expansión del gasto social como factor distributivo compensatorio puede enfrentar pronto restricciones de orden fiscal e institucional. El aumento de los gastos fiscales por concepto de pensiones es -como se vio más atrás en el gráfico 8-- la principal presión fiscal, y podría terminar manifestándose en contra del resto del gasto social. El hecho de que en 1995 y 1996 la educación básica haya absorbido menos del $5 \%$ de la expansión marginal del gasto social debería ser una 
campanada de alerta. De otra parte, las vacilaciones y dificultades del gobierno para avanzar en la modernización de la gestión social a través de una mayor descentralización, la competencia de los productores, la libertad de los usuarios y el uso de mecanismos racionales y predecibles de asignación de recursos, podrían revertir los logros en materia de equidad exhibidos por el gasto social en los últimos años.

ANEXO I

Indicadores distributivos en Colombia, 1938-1993

A. Empleo (miles de personas/años)

\begin{tabular}{|c|c|c|c|c|c|c|c|}
\hline & 1938 & 1951 & 1964 & 1971 & 1978 & 1988 & 1993 \\
\hline \multicolumn{8}{|l|}{ Agricultura } \\
\hline Jornaleros & 888 & 847 & 995 & 1002 & 1385 & 1750 & 1746 \\
\hline Campesinos & 700 & 869 & 1063 & 1178 & 1311 & 1632 & 1207 \\
\hline \multirow[t]{2}{*}{ Rentistas } & 459 & 336 & 400 & 380 & 401 & 426 & 464 \\
\hline & I 588 & 1716 & 2058 & 2180 & 2696 & 3382 & 2953 \\
\hline \multicolumn{8}{|l|}{ Actividad urbana } \\
\hline Asalariados & 750 & 1348 & 2073 & 2574 & 3499 & 4760 & 6666 \\
\hline Por cuenta propia & 225 & 362 & 494 & 926 & I 531 & 1792 & 3090 \\
\hline \multirow[t]{2}{*}{ Capitalistas } & 210 & 300 & 333 & 370 & 480 & 500 & 435 \\
\hline & 975 & 1710 & 2567 & 3500 & 5030 & 6552 & 9756 \\
\hline Total & 2563 & 3426 & 4625 & 5680 & 7726 & 9934 & 12709 \\
\hline
\end{tabular}

B. Ingresos reales (miles de pesos de 1995)

\begin{tabular}{lrrrrrrrr}
\hline & 1938 & 1951 & 1964 & 1971 & 1978 & 1988 & 1993 \\
\hline $\begin{array}{l}\text { Agricultura } \\
\text { Jornalerios }\end{array}$ & 733 & 876 & 974 & 1286 & 2047 & 1931 & 1927 \\
$\begin{array}{l}\text { Campesinos } \\
\text { Rentistas }\end{array}$ & 916 & 1250 & 1559 & 1837 & 2375 & 2119 & 1633 \\
& 1018 & 4521 & 6209 & 5898 & 5465 & 6115 & 5631 \\
$\begin{array}{l}\text { Actividad urbana } \\
\text { Asalariados }\end{array}$ & 1414 & 1438 & 2280 & 2948 & 3299 & 3342 & 3534 \\
$\begin{array}{l}\text { Por cuenta propia } \\
\text { Capitalistas }\end{array}$ & 1960 & 1368 & 1407 & 1799 & 2587 & 2561 & 3143 \\
\hline
\end{tabular}

C. Participaciones en el ingreso de los hogares

\begin{tabular}{|c|c|c|c|c|c|c|c|}
\hline & 1938 & 1951 & 1964 & 1971 & 1978 & 1988 & 1993 \\
\hline Agricultura & 0.432 & 0.445 & 0.387 & 0.314 & 0.291 & 0.273 & 0.176 \\
\hline Jornaleros & 0.160 & 0.099 & 0.073 & 0.071 & 0.101 & 0.098 & 0.075 \\
\hline Campesinos & 0.157 & 0.144 & 0.126 & 0.119 & 0.111 & 0.100 & 0.044 \\
\hline Rentistas & 0.115 & 0.202 & 0.188 & 0.124 & 0.078 & 0.075 & 0.058 \\
\hline Actividad urbana & 0.568 & 0.555 & 0.613 & 0.686 & 0.709 & 0.727 & 0.824 \\
\hline Asalariados & 0.260 & 0.258 & 0.358 & 0.419 & 0.413 & 0.460 & 0.522 \\
\hline Por cuenta propia & 0.108 & 0.066 & 0.053 & 0.092 & 0.142 & 0.133 & 0.215 \\
\hline Capitalistas & 0.200 & 0.232 & 0.202 & 0.175 & 0.155 & 0.135 & 0.087 \\
\hline Total & 1.000 & 1.000 & 1.000 & 1.000 & 1.000 & 1.000 & 1.000 \\
\hline Salarios & 0.420 & 0.356 & 0.432 & 0.490 & 0.514 & 0.557 & 0.596 \\
\hline Trabajo & 0.685 & 0.566 & 0.610 & 0.701 & 0.767 & 0.790 & 0.855 \\
\hline
\end{tabular}


ANEXO 1 (continuación)

D. Coeficientes Gini de desigualdad

\begin{tabular}{|c|c|c|c|c|c|c|c|}
\hline & 1938 & 1951 & 1964 & 1971 & 1978 & 1988 & 1993 \\
\hline \multicolumn{8}{|l|}{ Agricultura } \\
\hline Jornaleros & 0.2630 & 0.3491 & 0.3410 & 0.3105 & 0.3058 & 0.2833 & 0.3048 \\
\hline Campesinos & 0.4545 & 0.4241 & 0.4545 & 0.4490 & 0.5205 & 0.5357 & 0.5325 \\
\hline Rentistas & 0.5117 & 0.5139 & 0.5618 & 0.5612 & 0.5790 & 0.5991 & 0.5377 \\
\hline \multicolumn{8}{|l|}{ Actividad urbana } \\
\hline Asalariados & 0.2922 & 0.3754 & 0.4300 & 0.4404 & 0.3819 & 0.3517 & 0.3845 \\
\hline Por cuenta propia & 0.3415 & 0.4413 & 0.4801 & 0.501 & 0.5117 & 0.5452 & 0.5511 \\
\hline Capitalistas & 0.3893 & 0.5310 & 0.5790 & 0.5443 & 0.5435 & 0.5373 & 0.4768 \\
\hline \multicolumn{8}{|l|}{ Agregación factorjal } \\
\hline Laboral & 0.3553 & 0.3932 & 0.4586 & 0.4390 & 0.4111 & 0.4020 & 0.4491 \\
\hline No laboral & 0.5446 & 0.5217 & 0.5679 & 0.5540 & 0.5643 & 0.5713 & 0.5139 \\
\hline \multicolumn{8}{|l|}{ Agregación sectorial } \\
\hline Agrícola & 0.3910 & 0.5304 & 0.5701 & 0.5235 & 0.4826 & 0.4952 & 0.4846 \\
\hline No agrícola & 0.3900 & 0.5140 & 0.5332 & 0.5186 & 0.4703 & 0.4544 & 0.4553 \\
\hline Total & 0.4537 & $0.525 I$ & 0.5550 & 0.5268 & 0.4814 & 0.4765 & 0.4721 \\
\hline
\end{tabular}

\section{Bibliografía}

Altimir, O. (1994): Distribucion del ingreso e incidencia de la pobreza a lo largo del ajuste. Revista de la CEPAL, $\mathrm{N}^{\circ} 52$, LC/G.1824-P, Santiago de Chile, Comisión Econónica para América Latina y el Caribe (CEPAL).

(1996): Economic development and social equity: A Latin American prospective, Journal of Interamerican Studies and World Affairs, vol. 38, $\mathbf{N}^{\circ}$ 2-3, Miami, Florida, University of Miami.

Banco Mundial (1991): Informe sobre el desarrollo mundial 199I, Washington, D.C.

(1993): Informe sobre el desarrollo mundial 1993, Washington, D.C.

(1994): Poverty in Colombia, Washington, D.C

Berry, A. (1995a): The Social Challenge of the New Economic Era in Latin America, Working paper, University of Toronto, Center for International Studies.

(1995b): The macroeconomic context for policies, projects and programmes to promote social development and combat poverty in Latin America and the Caribbean, (Programa de las Naciones Unidas para el Desarrollo) (PNUD), Alleviation and Social Development Project, Working paper, $\mathrm{N}^{\circ} 1$, Nueva York, PNUD.

Berry, A. y J. Tenjo (1995): Estimación de las tasas de retorno a la educación en los años noventa, Santafé de Bogotá, Universidad de los Andes, mimeo.

Boltvinik, J. (1992): Conceptos y mediciones de la pobreza en América Latina: evaluación crítica en L. Beccaria y otros. América Latina: el reto de la pobreza, Santafé de Bogotá, PNUD.

Calderón, A. (1996): The Use of Vouchers for Secondary Schooling in Colombia: An Evaluation, Washington, D.C., FMl (Fondo Monetario Internacional).

Cardoso, E. y A. Helwege (1992): Below the line: Poverty in Latin America, World Development, vol. 20, $\mathrm{N}^{\circ} 1$, Oxford, Reino Unido, Pergamon Press plc.
Caro, B. y L. A. Rodríguez (1993): Evolución del sector informal en Colombia 1984-1992, Santafé de Bogotá, Departamento Nacional de Planeación.

Carrisoza, M. y A. Urdinola (1990): The political economy of poverty, equity and growth in Colombia, Washington D.C., Banco Mundial, mimeo.

Castañeda, T. (1992): El sistema de identificación de beneficiarios para el desarrollo de las políticas sociales, Santafé de Bogotá, Misión Socjal.

CEPAL (1991): Magnitud de la pobreza en América Latina en los años ochenia, Estudios e Informes de la CEPAL, $N^{\circ} 81$, LC/G. 1683-P, Santiago de Chile.

(1995): Panorama social de América Latina, 1995, LC/G.1886-P, Santiago de Chile. Publicación de las Naciones Unidas, $\mathrm{N}^{\circ}$, de venta S.95.II.G.17.

Colombia, Departamento Nacional de Planeación (1991): La revolución pacífica. Plan de desarrollo económico y social: 19901994, Santafé de Bogotá (FONADE).

(1995a): El salto social: bases para el Plan Nacional de Desarrollo 1994-1998, Santafé de Bogotá.

(1995b): Los costos económicos del conflicto armado en Colombia 1990-1994, Santafé de Bogotá, Utidad de Justicia y Seguridad, 7 de diciembre, mimeo.

Colombia, Ministerio de Salud (1994): Estimación de la carga de la enfermedad en Colombia, Santafé de Bogotá.

DANE (Departamento Administrativo Nacional de Estadística) (1994a): Cuentas nacionales de Colombia, Santafé de Bogotá. (1994b): Indicadores sociales en Colombia, Santafé de Bogotá.

Eastman, J. M.(1979): La distribución del ingreso en Colombia, Santafé de Bogotá, Cámara de Representantes.

Gálviz, T. (1989): Efectos de la violencia sobre las expectativas de vida en Colombia, Santafé de Bogotá, Instituto Nacional de Salud.

Hill, K. y A. Pande (1996): Trends in Child Mortality, 1960-1992: Estimates for 96 Developing Countries, Baltimore, 
Kakwani, N. C. (1997): Measurement of tax progressivity: An international comparison, The Economic Journal, vol. 87, $\mathrm{N}^{\circ} 345$, Oxford, Reino Unido, Royal Economic Society.

Kaztmann, R. (1989): La heterogeneidad de la pobreza: el caso de Montevideo. Revista de la Cepal, $N^{\circ} 37$, LC/G.1547-P, Santiago de Chile, CEPAL.

Londoȟo, J. L. (1989): La distribución del ingreso en 1988: una estimación con perspectiva histórica. Coyuntura social, $\mathrm{N}^{\circ} 1$, Santafé de Bogotá, Fundación para la Educación Superior y el Desarrollo (FEDESARROLLo).

(1995a): Distribución del ingreso y desarrollo económico: Colombia en el siglo $X X$. Santafé de Bogotá, Tercer Mundo Editores.

(1995b): 25 años de cambios distributivos en Colombia, Coyuntura económica, vol. XXV N ${ }^{\circ} 4$, Santafé de Bogotá, FEDESARROLLO.

(1995c): La distribución factorial y personal del ingreso en Colombia en los años noventa, Washington, D.C., mimeo. (1995d): Desigualdad, pobreza, democracia y polftica social, Washington, D.C., Banco Mundial, Departamento Técnico del Banco Mundial para América Latina.

(1996a): Los pobres podrian beneficiarse más de un gasto público más eficaz. Coyuntura economica, vol. XXVI, $\mathrm{N}^{\circ} 1$, Santafé de Bogotá, FEDESARROLLO.

(1996b): Pobreza, desigualdad y formación del capital kumano en América Latina, 1950-2025, Estudios del Banco Mundial sobre América Latína y el Caribe. Puntos de vista, Washington, D.C., Banco Mundial.

López, H. (1995): Mercado laboral urbano en Colombia: logros y desafios para el empleo y la productividad, Medellín, Colonbia, Corporación de Desarrollo para la Investigación y la Docencia Economica.

Lora, E. y M. L. Henao (1995): Efectos económicos y sociales de la legislación laboral, Coyuntura social, $\mathrm{N}^{\circ} 13$, Santafé de Bogotá, FEDESARROLLO.

Lora, Eduardo y R. Steiner (1995): Efectos distributivos de las políticas del gobierno de Gaviria: una estimación de equilibrio general, Santafé de Bogotá, FEDESARROLLo, mimeo.

Naciones Unidas (1995): Fourth Survey of Crime Trends and Operation of Criminal Justice Systems 1970-1995, Nueva York.

Okun, A. (1975): Efficiency and Equity: a tradeoff, Washington, D.C., The Brookings Institution.

Palacios, M. (1995): Entre la legitimidad y la violencia: Colombia 1875-1994, Santafé de Bogotá, Editorial Norma.

Pardo, R. (1996): De primera mano. Sobre violencia y conficto regional en Colombia, Santafé de Bogotá, Editorial Norma.

PNUD (Programa de las Naciones Unidas para el Desartollø). (1989): Medición de la pobreza: el enfoque de necesidades básicas insatisfechas, Nueva York.

(1995): Informe sobre desarrollo humano 1995, Nueva York
Reyes A. (1995): Series de empleo a nivel nacional 1976-1994, Santafé de Bogotá, Departamento Nacional de Planeación, junio, mimeo.

Robbins (1995): Trade, trade liberalization and inequality in Latin America and East Asia. Synthesis of Seven Country Studies. Cambridge, Harvard University, 1995 (mimeo).

Samper, E. (ed). (1976): La distribución del ingreso en Colombia, Santafé de Bogotá, (ANIF).

Sánchez, M. (1996): La evolución del gasto social en Colombia 1990-1995. Santafé de Bogotá, Departamento Nacional de Planeación/uds, abril.

Sarmiento E. (1993): Distribución del ingreso se deteriora: beneficios del crecimiento recaen sobre los ricos, El Espectador, Santafé de Bogotá, 21 de noviembre.

(1995): ¿Se hizo el milagro de la distribución del ingreso?, Coyuntura social, $\mathrm{N}^{\circ} 12$, Santafé de Bogota, FEDESARROLLO.

Sarmiento L. (1993): Política social y gasto público en los noventat ¿qué tan significativos son los cambios?, Coyuntura social, N ${ }^{\circ}$, Santafé de Bogotá, FEDESARrollo.

(1995): La cuestión social en Colombia: una propuesta estratégica, Santafé de Bogotá, Fundación Friederich Ebert, noviembre mimeo.

Selowsky, M. (1979): Who Benefits from Public Government? A Case Study of Colombia, Washington, D.C.. Banco Mundial

Sen, A. (1992): Inequality Reexamined, Cambridge, Massachussetts, Harvard University Press.

Tenjo, J. (1993): Evolución de los retornos a la inversión en educación 1976-1989, Revista de Planeación y Desarrollo, vol. XXIV Edición especial, Santafé de Bogotá, Departamento Nacional de Planeación.

Urrutia, M. (1985): Winners and Losers in Colombia's Economic Growth of the 1970's, Nueva York, Oxford University Press.

Urrutia, M. y A. Berry (1975): La distribución del ingreso en Colombia, Medellín, Colombia, La Carreta.

Urrutia M. y M. T. Ramirez (I993): Distribución del ingreso y la pobreza en Colombja: evolución reciente, Revista del Banco de la República, vol. LXVI, N 790, Santafé de Bogotá, Banco de la República (BRC).

Urrutia M., M. Misas, M. T. Ramírez y N. Rodríguez (1994): Distribución del ingreso en Colombia: una nueva estimación, Revista del Banco de la República, vol. LXVII, N ${ }^{\circ} 795$, Santafé de Bogotá, BRC.

Vélez, C. E. (1996): Gasto social y desigualdad: logros y extravíos, Santafé de Bogotá, Tercer Mundo Editores.

Vélez, C. E. y C. A. Medina (1995): Desigualdad, impuestos y subsidios: un esquema de descomposicion, Santafé de Bogotá, Departamento Nacional de Planeación, mimeo.

Williamson, J. (1985): Did British Capitalism Breed Inequalisy?, Londres, Allen \& Unwin. 